\title{
1 Protein turnover in the developing Triticum aestivum grain
}

2

3 Hui Cao, Owen Duncan, A. Harvey Millar*

4

5 ARC Centre of Excellence in Plant Energy Biology, University of Western Australia, Bayliss Building

6 M316, Crawley, WA 6009, Australia

7 School of Molecular Science, University of Western Australia, Bayliss Building M316, Crawley, WA

86009 , Australia

9

10

11

*Corresponding author: harvey.millar@uwa.edu.au

12

13

14

15

16

17

18

19

20

21

22

23

24

25

26

27

28

29 


\section{Abstract}

31 Protein abundance in cereal grains is determined by the relative rates of protein synthesis and protein

32 degradation during grain development. Through combining in vivo stable isotope labelling and in-

33 depth quantitative proteomics, we have measured the turnover of 1400 different types of proteins

34 during wheat grain development. We demonstrate that there is a spatiotemporal pattern to protein

35 turnover rates which explain part of the variation in protein abundances that is not attributable to

36 differences in wheat gene expression. We show that approximately $20 \%$ of total grain ATP production

37 is used for grain proteome biogenesis and maintenance, and nearly half of this budget is invested

38 exclusively in storage protein synthesis. We calculate that $25 \%$ of newly synthesized storage proteins

39 are turned over during grain development rather than stored. This approach to measure protein

40 turnover rates at proteome scale reveals how different functional categories of grain proteins

41 accumulate, calculates the costs of protein turnover during wheat grain development and identifies

42 the most and the least stable proteins in the developing wheat grain. 


\section{Introduction}

Wheat (Triticum aestivum L.) is a trusted source of protein and calories for human consumption and serves as the staple food for $30 \%$ of the human population ${ }^{1}$. Although global wheat production continues to grow steadily, it is not sufficient to meet predicted demand, especially when the global population is projected to exceed 9 billion by 2050 requiring an increase of wheat production by about $70 \%{ }^{2,3}$. To cope with such a challenge, researchers, breeders and wheat-processing industries have been working collaboratively to enhance yield while still maintaining grain-quality attributes such as grain protein content ${ }^{4,5}$.

While wheat protein content is dominated by glutenin and gliadin storage proteins ${ }^{6}$, it also includes thousands of other components spread through the endosperm, embryo and pericarp ${ }^{7,8}$. The abundance of high and low molecular weight glutenins determine dough elasticity, while gliadins contribute to dough extensibility ${ }^{9}$. A complex pattern of expression of the protein synthesis apparatus and many different types of proteases occur during the early and later stages of grain development ${ }^{10-}$

12. Further, wheat storage proteins are assembled, folded, aggregated and stabilised in the ER, and then follow a Golgi or ER route to vacuolar protein bodies ${ }^{13,14}$. As a consequence, the abundance of specific proteins products correlates poorly with expression of the encoding genes in both wheat ${ }^{15}$ and many plants ${ }^{16,17}$. Identification and quantification of additional factors that contribute to individual protein abundances and changes in abundance profiles over time are needed to better control wheat grain protein composition.

One such factor is protein turnover rate that dictates how quickly new plant proteins are synthesized while unwanted or dysfunctional proteins are degraded and recycled ${ }^{18-20}$. Study of protein turnover rate in plants have focused on either model plants such as Arabidopsis or non-food tissues of crops, such as seedlings or leaves ${ }^{19,21-26}$. These non-food plant proteomes can be studied in steady-state conditions influenced only by dilution through tissue growth ${ }^{18}$ and the relatively short lag period for introduction of stable isotopes makes calculating protein turnover measurements in these systems 
69 feasible ${ }^{19,26}$. In comparison, studying grain filling is complicated by the complex dynamics of protein

70 accumulation during development and the relative difficulty of rapidly introducing stable isotopes into

71 the spike ${ }^{27}$.

72 Here, we have overcome these technical and biological challenges to establish in vivo stable isotope

$73\left({ }^{15} \mathrm{~N}\right)$ labelling to enable protein turnover rates to be measured during wheat grain development. Using

74 this approach, we monitored synthesis and degradation rate of over 1400 different wheat protein

75 types during grain filling and calculated the ATP energy usage for protein synthesis and degradation.

76 Wheat grain protein turnover rates provide scientists and breeders with a quantitative and in-depth

77 understanding of how each wheat grain protein accumulates and a biotechnological pathway to craft

78 a lower cost grain proteome. 


\section{Results}

In vivo stable-isotope nitrogen $\left({ }^{15} \mathrm{~N}\right)$ labelling of wheat grain proteins. Measuring the synthesis and degradation of individual wheat proteins requires the labelling of new proteins in grains. We undertook this labelling by incorporation of the stable isotope of nitrogen, ${ }^{15} \mathrm{~N}$, into the amino acids used for their synthesis ${ }^{18,20}$. Wheat grain development includes cell division and expansion until 14 days post anthesis (DPA), grain filling (14 to 28 DPA), and desiccation and maturation (28 to 42 DPA $)^{28}$. To determine when during development the turnover rate of wheat grain proteins could be measured, four sets of wheat plants were raised in hydroponic medium with $\mathrm{N}$ salts of natural isotope abundance $\left(99.6 \%{ }^{14} \mathrm{~N}, 0.4 \%{ }^{15} \mathrm{~N}\right)$ until plants reached $7,14,21$ and 28DPA, respectively. The growth media of natural $\mathrm{N}$ isotopes was then replaced by heavy ${ }^{15} \mathrm{~N}$ labelled media $\left(2 \%{ }^{14} \mathrm{~N}, 98 \%{ }^{15} \mathrm{~N}\right)$. Grain samples were harvested after 7 days of continuous labelling (Extended Data Fig. 1a). Peptide mass spectrometry analysis showed that nearly $25 \%$ of $\mathrm{N}$ atoms in newly synthesised proteins in wheat grain were ${ }^{15} \mathrm{~N}$ after the 7-day labelling period, regardless of the grain DPA (Extended Data Fig. $1 \mathrm{~b}$ ). Broadly, calculations of the labelled protein fraction can be made independently of the $\%$ of ${ }^{15} \mathrm{~N}$ they contain, making this technique robust to differences in ${ }^{15} \mathrm{~N}$ incorporation rate ${ }^{18-20}$. We found younger grains showed a higher proportion of newly synthesised proteins in their total protein pool (labelled protein fraction, LPF) than older grains (Extended Data Fig. 1c). However, we know that at least 20\% of ${ }^{15} \mathrm{~N}$ incorporation is required to make high-quality protein turnover rates measurements with FDR $<1 \%^{26}$, we worked to achieve this basal rate by focusing on 7DPA-old grain as our first time point for subsequent labelling experiments. To capture the major events of grain development, samples of progressively labelled grain were collected after 3,7 and 10 days of continuous ${ }^{15} \mathrm{~N}$ labelling to span the 7DPA to 17DPA period (Extended Data Fig. 2a). A significant expansion was seen in grain size over 
One day lag time in labelling of wheat grain proteins. Incorporation of nitrogen into the developing grain requires long-distance transport from the roots through the phloem, before its assimilation, use estimated, we used both GC-MS analysis of free amino acids and LC-MS analysis of peptides to assess the ratio of heavy $(+1)$ to mono abundance of amino acids and peptides in samples collected in the first 30 hours of labelling. We found both amino acids and peptides of proteins remained at their natural abundance level before $24 \mathrm{~h}$ but rapidly rose between $24-30 \mathrm{~h}$ following ${ }^{15} \mathrm{~N}$ labelling (Extended Data Fig. 3b, c).

Grain respiration rate and ATP production. Protein production is a major user of cytosolic ATP generated through oxidative phosphorylation. Using a fluorophore-based oxygen sensor, we measured the grain respiration rate during grain development and found younger grains respired at twice the rate of older ones on a fresh weight basis (Fig. 1d). As cellular respiration is the primary ATP production source in wheat grain, and assuming a cellular ATP production ratio of $1 \mathrm{O}_{2}$ to $4.5 \mathrm{ATP}^{19}$, the total ATP production rate of a single grain was calculated to be $37,60,54$ and $54 \mu$ mol ATP per day for grains at 7, 10, 14 and 17DPA, respectively (Supplementary Data 1d). development. As the proteome of the wheat grain is not in a steady-state during filling, we needed to obtain individual fold changes in protein abundance (FCP) values for each protein of the wheat grain. To do this a spike-in procedure was developed that involved adding a standard amount of a fully ${ }^{15} \mathrm{~N}$ labelled wheat grain standard (see methods) to four grains from each time point. This helps to define proteins rapidly accumulating in the grain and exclude the effect of differential starch accumulation on the measurements (Extended Data Fig. 2b). Using this approach, quantification of the abundance change of 2307 non-redundant grain proteins were measured using data from over 71,000 
quantitative data set showed that grain samples separated according to their DPA with the first principal component explaining nearly $94 \%$ of the variation. Only minor variation was observed in the second principal component and biological replicate samples of the same time point were closely clustered together (Extended Data Fig. 5a). Over half of the identified proteins increased in abundance $\geq 2$-fold from 7DPA to 17DPA, with a few exceptions that showed the opposite pattern, consistent with net protein accumulation during grain development (Fig. 2a). Quantitative abundance changes for different proteins during grain development varied from 0.018 -fold to 126 -fold. Examples shown in Fig $2 \mathrm{~b}$ illustrate the dynamics of different protein groups such as ribosomal proteins (fold change < 3 over 10 days) and storage proteins (fold change $>25$ on average and up to 126 over 10 days). proteins in each). These showed a median fold change value of 1.38-, 2.31- and 2.45 at 10, 14 and 17DPA compared to 7DPA (Fig. 2c and Extended Data Fig. 6). Exceptions were found in the categories of storage proteins, major $\mathrm{CHO}$ metabolism and stress response, where fold change values significantly higher than the median were observed. These data are consistent with biogenesis and accumulation of starch and storage proteins being major events during grain development and moisture loss in ripening and maturation being a post-anthesis stress ${ }^{31}$. Protein categories associated with protein folding, TCA cycle, DNA synthesis and photosynthesis showed lower fold change than the median, likely because they were less active cellular pathways during grain development. Together this evidence showed clear temporal patterns in the regulation of protein abundance during grain development.

Calculating wheat grain protein synthesis and degradation rates during grain development. The labelled protein fraction (LPF) is an instantaneous measurement of the ratio between existing and new protein molecules for each individual proteins of interest at a given point of time. This information is derived from the ratio of peptides for a protein with greater than natural abundance (labelled) to the 
measurements are derived from quantitation of the deviation of the isotopic envelope from what would be expected of natural abundance peptides of a particular sequence ${ }^{19,32}$. LC-MS/MS results

(RSD) for each protein at a given time point was less than $11 \%$ across all three time points correlation of LPF between biological replicates ranging from 0.81 to 0.95 (Extended Data Fig. 5g). PCA analysis suggested that up to $97 \%$ of the variation observed could be explained by the first principal component alone (Extended Data Fig. 5d). Through combining the individual fold change in protein (FCP) and LPF values for specific proteins, we then calculated protein synthesis rates and degradation rates for 1447 non-redundant proteins (Supplementary Data 5b). Relative protein synthesis rates (Ks/A; where $K_{s}$ is the synthesis rate constant, and $A$ the abundance of protein) varied nearly 100 fold; ranging from $0.057 d^{-1}$ to $5.27 d^{-1}$ with a median of $0.35 d^{-1}$. By contrast, protein degradation rates $\left(K_{D}\right.$; where $K_{D}$ is the degradation rate constant) had a median of $0.11 \mathrm{~d}^{-1}$ and ranged from effectively zero up to $0.94 \mathrm{~d}^{-1}$. The latter indicates a range of proteins in grain with half-lives of less than one day. data set by their subcellular location retrieved from a database of crop proteins with annotated locations; $\mathrm{CropPAL}^{33}$. We reassigned storage proteins into vacuole because once assembled in ER, storage proteins are transported to storage protein vacuoles (PSV) ${ }^{34}$. Based on this, vacuole proteins, predominantly storage proteins, showed higher median synthesis and degradation rates than other subcellular structures. The same pattern was found in subcellular protein sets of the peroxisome, Golgi apparatus and extracellular secreted proteins (Et), but the opposite pattern was seen in protein sets located in the mitochondrion, cytosol, plastid and the endoplasmic reticulum (ER) (Fig. 3a). These observations generally agreed with published data from Arabidopsis leaves which showed organellar 
proteins that are physically separated from the cytosolic proteolysis system have relatively lower degradation rate, while cellular structures such as the Golgi apparatus have a frequently updated protein complement and a relatively higher turnover rate ${ }^{19}$.

When the data were arranged by MapMan functional category bins, most of the 37 major groups maintained a median $K_{S} / A$ of $0.35 \pm 0.15 \mathrm{~d}^{-1}$ and median $K_{D}$ of $0.11 \pm 0.05 \mathrm{~d}^{-1}$ (Fig. 3b). However, exceptions were found, notably stable photosynthesis proteins had a median $\mathrm{K}_{\mathrm{s}} / \mathrm{A}$ of $0.24 \mathrm{~d}^{-1}$ and median $K_{D}$ of only $0.03 \mathrm{~d}^{-1}$, while storage proteins had a median $\mathrm{K}_{S} / \mathrm{A}$ of $2.17 \mathrm{~d}^{-1}$ and median $\mathrm{K}_{\mathrm{D}}$ of 0.48 $\mathrm{d}^{-1}$, indicating rapid synthesis and degradation cycling of a portion of storage proteins in developing grains. Variation of protein turnover rates was also observed for proteins located in the same organelle or subcellular structure but which belonged to different functional categories, or vice versa, such as cytosolic proteins involved in ATP synthesis, protein folding and protein synthesis, or RNA regulation factors located in the cytosol and nucleus (Fig. 3b). To better understand the connection between protein functional roles and their turnover rates, we compared turnover rate profiles between three sets of rapidly-cycling proteins and three more stable house-keeping protein sets. The $\mathrm{K}_{\mathrm{s}} / \mathrm{A}$ of the rapidly-cycling proteins gradually increased or stayed steady over development, while a much lower synthesis rate and decreasing $\mathrm{K}_{\mathrm{S}} / \mathrm{A}$ over development was observed for more stable house-keeping functional categories (Fig. 3c). As expected, much lower $K_{D}$ was determined for housekeeping proteins in comparison with rapidly-cycling proteins, but unlike protein synthesis rate, both protein types shared a similar pattern over development, notably that $K_{D}$ dropped from its peak at 10DPA to its lowest level at 14DPA followed by a slight increase by 17DPA. and the 20 most rapidly degraded proteins (30\%) in wheat grains; this included gliadins, globulins, high-molecular-weight glutenin subunits (HMW-GS) and low-molecular-weight glutenin subunits 
most rapidly degraded list. An alpha-amylase inhibitor (TraesCS6D01G000200.1) topped the degradation rate list and had a calculated half-life of only $0.74 \mathrm{~d}^{-1}$.

To facilitate further comparisons, we used filters to select a set of 149 wheat proteins that were fast $K_{S} / A$ and $\left.K_{D}, F F\right)$ (Extended Data Fig. 7a). Functional category analysis of these sets showed that the house-keeping proteins mainly participated in photosynthesis, DNA synthesis and glycolysis; while induced but stable proteins participated in major $\mathrm{CHO}$ metabolism, transport and amino acid synthesis proteins; and the rapidly-cycling protein set was dominated by storage proteins, proteins involved in stress response and proteins involved in protein degradation (Extended Data Fig. 7b-d). proteins, we separately quantified the abundance of 5550 grain protein groups in endosperm, embryo and pericarp (Extended Data Fig. 8 and Supplementary Data 6). These proteins were then assigned into seven categories based on their protein abundance profile using the definition and equations explained in the Methods section. Forty percent of these proteins were found evenly balanced in their abundance across grain tissues, $32 \%$ were assigned as tissue-specific proteins (7\% for endosperm, and $12.5 \%$ for embryo and pericarp, respectively) and $\sim 29 \%$ as tissue-suppressed proteins, i.e. proteins present two tissues but low in the third (14\% for endosperm, and $7.5 \%$ for embryo and 
fold change in abundance and decreasing in net accumulation rate over time. In comparison, embryo-

232

233 specific proteins had an increasing net accumulation rate over development but very low turnover rates and fold change in abundance values (Fig. 4c). The proteins with tissue-balanced profiles, showed moderate fold changes and net accumulation rates remained stable over development (Fig. 4c). This pattern was also observed to a lesser extent in protein groups suppressed in a specific tissue (Extended Data Fig. 9).

ATP Energy budget for wheat grain proteome synthesis and maintenance. The ATP energy cost for both synthesis and degradation of 1140 proteins in the wheat grain proteome was calculated through combining Intensity Based Absolute Quantification (iBAQ) values (Supplementary Data 7a), protein turnover rates, amino acid length, and the ATP cost per amino acid residue for protein synthesis and protein degradation ${ }^{35-37}$ (Supplementary Data $7 b$ ). This revealed that during grain development, each grain invested $20 \%$ of its total ATP production on protein biogenesis and maintenance. The ATP budget for protein synthesis $\left(9.8 \mu \mathrm{mol} \mathrm{grain}^{-1} \mathrm{~d}^{-1}\right)$ was nearly 9 times larger than for protein degradation (1.2 $\mu$ mol grain ${ }^{-1} d^{-1}$; Fig. 5a).

Grouping the ATP usage data by the subcellular location of each protein allowed us to assess the relative energy cost of maintaining different subcellular structures in the wheat grain. Maintaining the proteins of the vacuole (the destined location of storage proteins) used one third of the total ATP budget for protein synthesis although this group only contained 24 unique groups of proteins. This was followed by the largest category, cytosolic proteins (comprising 469 protein groups), that cost $\sim 25 \%$ of the ATP, and the plastid and Golgi apparatus each cost $\sim 13 \%$ of the ATP used for protein synthesis (Fig. 5b). The cytosol proteome cost $34 \%$ of the total ATP for protein degradation, which was nearly twice that of the vacuole (17.8\%). Expressing the ATP usage rate as nmol per million protein copies per grain per day (nmol ATP mcopy ${ }^{-1}$ grain $^{-1} d^{-1}$ ), the vacuole proteome was the most expensive for protein synthesis on a location basis, costing $144 \mathrm{nmol}$ ATP mcopy ${ }^{-1}$ grain $^{-1} \mathrm{~d}^{-1}$, which was 15 times higher than the lowest cost compartment, the nucleus, at only 9.3 nmol ATP mcopy ${ }^{-1}$ grain $^{-1} \mathrm{~d}^{-1}$. 
Peroxisomes topped the list of protein degradation energy costs, consuming $12 \mathrm{nmol}$ ATP mcopy ${ }^{-1}$ grain ${ }^{-1} \mathrm{~d}^{-1}$, while the cytosol, by contrast, only consumed $2.2 \mathrm{nmol}$ ATP mcopy ${ }^{-1}$ grain $^{-1} \mathrm{~d}^{-1}$ for this purpose.

When the data was grouped by functional category, we observed that storage proteins and enzymes of major $\mathrm{CHO}$ metabolism were the most costly in terms of both protein synthesis and degradation, together they used half the energy budget of total protein synthesis and a quarter of the total energy budget for protein degradation (Fig. 5c). Storage proteins were the most expensive functional category in terms of synthesis and maintenance of proteins, costing $152 \mathrm{nmol}$ ATP mcopy ${ }^{-1}$ grain $^{-1} \mathrm{~d}^{-1}$ for synthesis and additional $9 \mathrm{nmol}$ ATP mcopy $^{-1}$ grain $^{-1} \mathrm{~d}^{-1}$ for degradation. Less costly protein synthesis and maintenance expense was evident for ribosomal proteins ( 7 nmol ATP mcopy ${ }^{-1}$ grain $^{-1}$ $\mathrm{d}^{-1}$ for synthesis and $0.9 \mathrm{nmol}$ ATP mcopy ${ }^{-1}$ grain $^{-1} \mathrm{~d}^{-1}$ for degradation). As expected, the 20 highest cost proteins were predominately storage proteins and major $\mathrm{CHO}$ metabolism proteins, among which the highest energy cost for an individual protein was an 11S globulin (TraesCS1A01G066100.1) that cost nearly $2 \%$ of grain ATP in its production during this stage of grain development (Extended Data Table 2).

Collectively, storage proteins dominated the wheat grain proteome in terms of abundance, fold change in protein, protein turnover rates and ATP energy usage; but this prominence builds over time. The grain invested only $10 \%$ of its total ATP energy budget for protein synthesis on the formation of storage proteins at the early grain filling stage (10DPA), but this subsequently grew 4.5 times in the next 4 days, reaching $45 \%$ of the total ATP budget for protein synthesis by 14 DPA, and settled at $36 \%$ by 17DPA (Fig. 5d). The ATP energy budget for degradation of storage proteins showed a similar pattern, increasing at the early stage of grain filling and decreasing at later stages, although it remained at a relatively high level over time. The machinery of major $\mathrm{CHO}$ metabolism, which is needed for starch synthesis, showed a rather stable energy usage over time compared to storage 
glycolysis showed a relatively stable energy usage over time and only consumed a minor proportion of ATP production in the grain (Fig. $5 \mathrm{~d}$ ).

Wheat storage proteins accumulation during grain filling. To illustrate the complexity of 7DPA to 17DPA we integrated 6 different measures into a single radar graphic (Fig. 6a). Our findings indicated that except for globulin 1 encoding genes which peaked at 30DPA, the mRNA of key storage proteins were most abundant at the early grain filling stage and were temporally offset from protein accumulation. A common pattern in synthesis rates and biogenesis energy cost (CostSyn) was shared between storage protein families; they reached the highest level at 14DPA and remained at this level until at least 17DPA. In comparison, significantly higher degradation rates and energy consumption were measured at the pre-grain filling stage (10DPA) than the grain filling stage (from 14DPA). Collectively these features resulted in a rapid accumulation in storage protein abundance, which increased over 20-fold on average and up to 90 -fold for some storage protein isoforms from 10DPA to 17DPA (Fig. 6b).

\section{Discussion}

In this study, we provide an extensive and quantitative understanding of how different wheat grain proteins accumulate during grain development. The resulting protein turnover data allows the costs of individual proteins, protein functional groups, and cell structures during grain development to be calculated, providing an innovative foundation for grain protein engineering strategies. 
developmental change in protein composition ${ }^{19,26,38}$, which is not the case in grain filling. We solved these two problems by experimentally calculating a $28 \mathrm{~h}$ lag time for ${ }^{15} \mathrm{~N}$ incorporation (Extended Data

Fig. 3) and measuring the fold change in abundance for each protein of interest during grain development using a spike-in of a fully ${ }^{15} \mathrm{~N}$ labelled proteome (Fig. 2 and Extended Data Fig. 6). This has allowed not only the protein turnover rates of over a thousand proteins to be determined, but to do so in a background of proteins changing in relative abundance over a 0.018 -fold to 126 -fold range.

As autotrophs, plants have access to a large source of ATP via photosynthesis in source leaves. However, the ATP yielded by this process is largely invested in sucrose synthesis that is transported to sink tissues, which leaves oxidative phosphorylation by respiration as the primary source for cytosolic ATP-dependent processes like protein synthesis and degradation ${ }^{19,39}$. Based on this we calculated the proportional energy cost for synthesis and degradation of the wheat grain proteome during grain filling based on grain respiration rates (Fig. 5). Our data show that approximately $20 \%$ of total grain ATP production through respiration is used for grain proteome biogenesis and maintenance, and nearly half of this budget is invested exclusively in storage protein synthesis. This proportion was similar in size to reports of the cost of Arabidopsis leaf protein turnover which varied from $16-42 \%$ of total ATP depending on the age of the examined leaf ${ }^{19}$. However, in grains this ATP investment is cocommitment with the high ATP demand of starch synthesis at the same times during development ${ }^{40,41}$. Collectively, ATP provision to protein synthesis and degradation and the starch synthesis represent an energy constraint that will dictate the relative investment in starch and protein in the final grain.

Dough rheological properties and bread-making quality in wheat are primarily determined by gluten quantity 9 . In our development analysis, four storage protein families that are key components of gluten polymers, namely HMW-GS, LMW-GS, gliadin-like avenin and gamma-gliadin, represent $85 \%$ of storage protein abundance (Fig 6c and Supplementary Data 8); consistent with previous studies reporting $80-90 \%$ of total grain protein is gluten polymers ${ }^{6,42}$. Extensive previous studies have also demonstrated that gluten quality, both the ratio of gliadin/glutenin and the ratio of HMW-GS/LMW- 
GS, strongly influences dough viscosity and elasticity, thus governing bread-making quality traits ${ }^{43-45}$.

Unlike the ratio of HMW-GS/LMW-GS, the ratio of gliadin/glutenin remained stable during grain

between 10 and 17 DPA. Wheat storage proteins are generally assembled, folded and aggregated in

the endoplasmic reticulum (ER), followed by a trafficking event mediated by protein bodies to vacuoles for storage through either a Golgi-vacuole route or the ER-vacuole route ${ }^{13,14}$. Previous evidence has suggested that storage proteins are stabilized during the processing within the ER due to the formation of complex polymers through disulphide and noncovalent bonds (inter-and/or intrachain bonds $)^{14,46}$. Dominguez and Cejudo showed that extractable wheat grain endoprotease activity reached its maximum at 15 DPA and then decreased afterwards ${ }^{10}$. Likewise, Nadaud et al showed grain proteolysis activity peaked at approximately 10DPA, and showed a decrease pattern over the following 4 days $^{11}$. Our data also indicate a significant decrease in protein degradation machinery of the endomembrane system from 10DPA to 17DPA (Supplementary Data 7c). These high degradation rates of storage proteins detected at 10DPA are not the case for all storage protein isoforms (Fig. 6b and Supplementary Data 7c), providing a breeding or biotechnological pathway to select for lower cost storage proteins with lower degradation rates.

Extensive effort has been placed into assessing the correlation between transcript level and protein abundance, however only $\sim 40 \%$ of the variation in protein abundance is typically explained by transcript data in eukaryotes, including plants ${ }^{16,17,47,48}$. In wheat there is only a $32 \%$ concordance between protein and transcript expression profiles observed during grain development ${ }^{15}$. This atlas of wheat grain protein turnover rates contributes to explaining the remaining variation in protein abundance not correlated to transcript levels. As an atlas iy shows that despite variation of turnover 
rate for different proteins approaching 100 fold, protein turnover rates are highly correlated with their changing profiles of FCP over time when a net accumulation rate calculation is considered as the key driver of protein abundance alterations (Fig. 3 and Extended Data Fig. 10). It is also known that spatiotemporal regulatory mechanisms broadly exist in live-systems and play essential roles in protein abundance regulation to meet various biological scenarios ${ }^{19,49-51}$. This pattern is also evident in our other protein groups drives the preferential accumulation of storage proteins as one of the largest cellular events during grain filling (Fig. 2-4).

Overall this study provides a comprehensive and in-depth view of which key storage proteins accumulation during pre- and the early-mid grain filling stage. In addition, the quantitative data for non-storage proteins provides insights into a wide range of biological events during wheat grain development, such as the protein machinery for starch accumulation and the initiation of desiccation stress responses. Future studies will be needed to reveal why wheat grains partake in cycles of protein synthesis and degradation and find approaches to alter this cycling such as knockout of unstable storage proteins and expression of more stable versions using either conventional cross breeding approaches or gene editing technologies. Success in this pursuit could help increase grain protein content, improve energy use efficiency of protein production, and help meet the unprecedented food demand for sustainable plant-based protein production in modern agriculture.

\section{Methods}

Plant materials and growth condition. Wheat (Triticum aestivum) plants of cv. Wyalkatchem, were grown in an indoor chamber under $16 / 8$-h light/dark conditions with $26 / 18^{\circ} \mathrm{C}, 60 \%$ humidity and light 377 intensity of $800 \mu \mathrm{mol} \mathrm{m} \mathrm{m}^{-2}$. The hydroponic growth system used for plant growth is described by Munns and James ${ }^{52}$. Fifty litres Hoagland solution was used for 24 plants and changed weekly ${ }^{8}$. Seeds were vernalized under $4^{\circ} \mathrm{C}$ for 3 days before being transferred to the growth chamber followed by 3 
hydroponic growth system. Plants were firstly grown with natural abundance $\mathrm{N}$ medium, which was then replaced with ${ }^{15} \mathrm{~N}\left({ }^{15} \mathrm{NH}_{4}{ }^{15} \mathrm{NO}_{3}, 98 \%\right.$, Sigma fine chemicals) medium for a labelling programme when plants reached the required growth stage (eg. 7DPA). Plants were rinsed three times with distilled deionized water before being transferred to the ${ }^{15} \mathrm{~N}$ medium. A set of fully labelled plants to generate the spike-in standard samples were grown with ${ }^{15} \mathrm{~N}$ medium at all times after germination. at multiple time points as shown in Extended Data Fig. 1 and 2. Only 8 grains from the middle of the ear (both floret 1 and 2) were collected in each case. Grain tissues of embryo, endosperm and pericarp were hand-dissected by scalpel. Due to the challenge of separating embryo from endosperm in young grain, only 14 and 17DPA-old grain were used for dissection and tissue samples of two time points were pooled together. Samples were snap frozen in liquid nitrogen and stored in $-80^{\circ} \mathrm{C}$ for further protein extraction.

Grain respiratory oxygen consumption rate measurement. Respiration rates of single premature and the formula reported by Scafaro et al in $2017^{53}$. The representative $\mathrm{R}_{\mathrm{N}}$ was calculated using the $\mathrm{O}_{2}$ consumption slope in the $2 \mathrm{~h}$ window from 1-3 $\mathrm{h}$. Total ATP production of a single wheat grain at each growth stage was also estimated based on the ATP production rates of $1 \mathrm{O}_{2}$ to $4.5 \mathrm{ATP}^{19}$.

Spike-in approach for individual wheat grain FCP measurement. To precisely measure individual FCP 
labelled fine sample powder of $100 \mathrm{mg}$ was spiked into four unlabelled grains at each time point as an and FCP measurement.

Sample preparation. A chloroform/methanol extraction protocol ${ }^{54}$ was applied for total protein extraction in this study. Briefly, $200 \mathrm{mg}$ sample powder generated by extensive grinding in liquid $\mathrm{N}_{2}$ was mixed with $400 \mu \mathrm{L}$ extraction buffer (125 mM Tris-HCl pH 7.5, 7\% (w/v) SDS, 0.5\% (w/v) PVP40, Roche protease inhibitor cocktail (Roche, 1 tablet per $50 \mathrm{ml}$ )) and rocked on ice for $10 \mathrm{~min}$. After a centrifugation at $10,000 \mathrm{~g}$ for $5 \mathrm{~min}$, about $200 \mu \mathrm{L}$ supernatant was transferred into a new $2 \mathrm{ml}$ eppendorf tube, followed by protein precipitation through mixing the supernatant with $800 \mu \mathrm{L}$ methanol, $200 \mu \mathrm{L}$ chloroform and $500 \mu \mathrm{L}$ distilled deionized water. The pellet was washed twice using methanol and then incubated with $90 \%(\mathrm{v} / \mathrm{v})$ acetone at $-20{ }^{\circ} \mathrm{C}$ twice for at least 1 hour each time. After drying at room temperature, protein pellet was resuspended using resuspension buffer $(50 \mathrm{mM}$ Ambic, 1\% (w/v) SDS and $10 \mathrm{mM}$ DTT). Protein concentration was quantified by an amido black method $^{55}$.

Proteins $(200 \mu \mathrm{g})$ were incubated with $20 \mathrm{mM}$ DL-dithiothreitol for $20 \mathrm{~min}$ in darkness at room temperature, followed by a second incubation with $25 \mathrm{mM}$ iodoacetamide for $30 \mathrm{~min}$ in darkness at room temperature. After diluting the SDS to its working concentration at $0.1 \%(\mathrm{w} / \mathrm{v})$ via adding distilled deionized water, proteins were digested overnight using trypsin (Promega, Sequencing Grade Modified Trypsin, USA) at $37^{\circ} \mathrm{C}$ with protein-trypsin ratio of 50:1. The SDS removal and high-pH, reversed phase peptide fractionation for digested peptide solution ${ }^{56}$ were conducted on an off-line HPLC (1200 series, Agilent Technologies) combining with two J4SDS-2 guard columns (PolyLC) and an XBridge $^{\mathrm{TM}} \mathrm{C} 183.5 \mu \mathrm{m}, 436 \times 250 \mathrm{~mm}$ column (Waters). The pump flow was set at $0.5 \mathrm{ml} / \mathrm{min}$ using 
min. In total, 64 fractions for each sample were collected from 15 to 79 min in 1 min windows. The

first 12 and last 4 fractions were discarded and the rest of the fractions in the same column of the 96 well plate were combined together. The final 12 fractions of each sample were dried down through a vacuum centrifuge and store in $-80^{\circ} \mathrm{C}$ for further mass spectrometry analysis.

LC-MS data acquisition and processing. Peptide fractions were resuspended with $25 \mu \mathrm{L}$ of $5 \%(\mathrm{v} / \mathrm{v})$ acetonitrile and $0.1 \%(\mathrm{v} / \mathrm{v})$ formic acid in HPLC grade water followed by a filtering step using $0.22 \mu \mathrm{m}$ centrifugal filters (Millipore). Purified peptide suspensions ( $2 \mu \mathrm{L}$ each) were injected into a HPLC-chip (Polaris-HR-Chip-3C18, Agilent Technologies) through a capillary pump with a flow at $1.5 \mu \mathrm{L} / \mathrm{min}$. Peptides were eluted from the C18 column online into an Agilent 6550 Q-TOF. Gradients were generated by a 1200 series nano pump (Agilent Technologies) with the nano flow at $300 \mathrm{nl} / \mathrm{min}$, of which $5-35 \%(\mathrm{v} / \mathrm{v})$ solution $\mathrm{B}(0.1 \%(\mathrm{v} / \mathrm{v})$ formic acid in acetonitrile) in $35 \mathrm{~min}, 35-95 \%$ in $2 \mathrm{~min}$ and 95 $5 \%$ in 1 min. Parameters setting in MS acquisition was as described previously ${ }^{8}$. In total, LC-MS data of 516 fractions were successfully collected (Extended Data Fig. 2d). The primary MS data files are available via ProteomeXchange with identifier PXD022231.

To measure individual FCP of wheat grain proteins during grain development, LC-MS data stored in Agilent .d files of 288 fractions of spike-in and unlabelled samples (144 fractions each) were first converted to mzML files using the online Trans Proteomic Pipeline (TPP, v.5.2.0) ${ }^{57}$. The Comet search of above mzML files was conducted against protein database from IWGSC (v.1.0, 137029 sequence $)^{58}$ using decoy search, $20 \mathrm{ppm}$ peptide mass tolerance and maximum 2 missed cleavage ${ }^{59}$. Further PeptideProphet search was performed for each replicate at each time point (eg. 12 fractions of replicate 1 of spike-in data at 7DPA and 12 fractions of replicate 1 of unlabelled data at 7DPA) and results were merged into single analysis file using PPM to accurate mass binning and decoy hits to pin down negative distributions. Protein identification and corresponding LPF for each protein were obtained by using an in-house pipeline written in R, of which $12 \mathrm{mzML}$ files of spike-in data for each 
probability $>0.8, \mathrm{FDR}<3 \%$, rsd $\leq 25 \%$ or $\mathrm{sd} \leq 25 \%$ of overall mean LPF were applied for peptide list,

while filters of probability $>0.95, \mathrm{FDR}<1 \%$, rsd $\leq 25 \%$ or sd $\leq 25 \%$ of overall mean LPF, independent of each protein.

The LC-MS data of unfractionated 30-h labelling samples (Extended Data Fig. 2) were processed through Agilent MassHunter Workstation (v.10.1) to determine the ratio of heavy (+1) to mono abundance of peptides. Peptide peak area was used as peptide relative abundance.

GC-MS data acquisition and processing. Grain sample powder of $30 \mathrm{mg}$ were mixed with $250 \mu \mathrm{L}$ $75^{\circ} \mathrm{C}$ and $950 \mathrm{rpm}$ for $10 \mathrm{~min}$. After mixing with $125 \mu \mathrm{L}$ of chloroform and $250 \mu \mathrm{L}$ of distilled deionized water, sample solutions were centrifuged for $15 \mathrm{~min}$ at 2,000g, of which $50 \mu \mathrm{L}$ of supernatant was transferred to a new tube and dried out using a vacuum centrifuge. Sample derivatization started with an incubation in $20 \mu \mathrm{L}$ of $20 \mathrm{mg} \mathrm{mL}^{-1}$ methoxyamine hydrochloride in pyridine for $2 \mathrm{~h}$ at $37^{\circ} \mathrm{C}$, followed by a second incubation in $20 \mu \mathrm{L}$ of $N$-methyl- $N$-(trimethylsilyl)-trifluoroacetamide (SIGMA, USA) for 30 $\min$ at $37^{\circ} \mathrm{C}$. Incubations were conducted on a thermomixer at $950 \mathrm{rpm}$. Volume of $40 \mu \mathrm{L}$ derivatized sample was transferred to glass vials for GC-MS analysis. Metabolites samples of $1 \mu \mathrm{L}$ were injected into an Agilent 7890A gas chromatograph coupled with a Varian CP9013-Factor 4 column (40 m 3 $0.25 \mathrm{~mm}$ i.d.) and an Agilent 5975 quadrupole mass spectrum detector. GC-MS data acquisition was performed following descriptions reported by $\mathrm{O}^{\prime}$ Leary and co-workers ${ }^{60}$. GC-MS data were processed and analysed using Agilent MassHunter Workstation (v.10.1) as mentioned earlier. 
Label free quantification using MaxQuant. The same unlabelled LC-MS data of 144 fractions were

processed by searching against IWGSC database through MaxQuant (v.1.6.1.0,

http://www.maxquant.org/) with the iBAQ quantitation algorithm, $20 \mathrm{ppm}$ peptide mass tolerance, relative abundance. Proteins with a relative contribution $\geq 66 \%$ in one tissue and $\geq 3$-fold that in the other two tissues are defined as tissue-specific proteins (shown close to triangle vertices), while non tissue-specific proteins with a relative contribution $\leq 17 \%$ of a tissue are defined as tissue-suppressed proteins. The remaining proteins are found relatively evenly balanced across grain tissues. Protein category definition was further confirmed by the independent Tau method ${ }^{63}$ (Extended Data Fig. 8c).

500 Ternary diagram visualization was performed using the ggtern R package ${ }^{64}$. 
$504 \quad \frac{K_{S}}{A}=-\frac{F C P-e^{-K_{D} \cdot t}}{1-e^{-K_{D} \cdot t}} \cdot K_{D}$

equation (5)

505 Where $A$ is the protein starting abundance at the beginning of the labelling programme (7DPA).

506 According to previous reports, protein synthesis cost was 5.25 ATP per residue including ribosome

507 translation, protein transport and amino acid biosynthesis ${ }^{35,37}$, while the cost for protein degradation

508 was approximately 1.25 ATP per residue through proteasome degradation pathway ${ }^{36}$. The ATP energy

509 cost for protein turnover were therefore estimated by combining absolute protein copy number,

510 amino acid length, protein turnover rates, grain ATP production and ATP energy cost per residue. The

511 full-length intact peptide sequences of Chinese Spring glutenin subunits and gliadins were referred to

512 long read sequencing data ${ }^{65,66}$. Detailed step-by-step explanations of both protein turnover rates and

513 its ATP energy cost calculation were previously reported ${ }^{19,67}$.

514 Gene expression data retrieval. Gene expression data of the key storage proteins were downloaded

515 from the Wheat Expression Browser website (http://www.wheat-expression.com/) ${ }^{68,69}$. Only Chinese

516 Spring grain tissue data at 2, 14 and 30DPA under non-stress conditions (choulet_URGI) were used in

517 this study.

518 Statistical analysis. Data processing, statistical analysis and visualization were performed in the R

519 environment (v.3.5.1). Statistical tests and replicate number are as shown in figure and figure legends. 


\section{Reference}

522 1. Shewry, P. R. \& Hey, S. J. The contribution of wheat to human diet and health. Food Energy

2. Foley, J. A. et al. Solutions for a cultivated planet. Nature 478, 337-342, doi:10.1038/nature10452 (2011).

3. Tilman, D., Cassman, K. G., Matson, P. A., Naylor, R. \& Polasky, S. Agricultural sustainability and intensive production practices. Nature 418, 671-677, doi:10.1038/nature01014 (2002).

4. Voss-Fels, K. P. et al. Breeding improves wheat productivity under contrasting agrochemical input levels. Nat Plants 5, 706-714, doi:10.1038/s41477-019-0445-5 (2019).

5. Muqaddasi, Q. H. et al. Prospects of GWAS and predictive breeding for European winter wheat's grain protein content, grain starch content, and grain hardness. Scientific reports 10, 12541, doi:10.1038/s41598-020-69381-5 (2020).

6. Shewry, P. R. Wheat. Journal of experimental botany 60, 1537-1553, doi:10.1093/jxb/erp058 (2009).

7. Cao, H. et al. Distinct metabolic changes between wheat embryo and endosperm during grain development revealed by 2D-DIGE-based integrative proteome analysis. Proteomics 16, 1515-1536, doi:10.1002/pmic.201500371 (2016).

8. Duncan, O., Trosch, J., Fenske, R., Taylor, N. L. \& Millar, A. H. Resource: Mapping the Triticum aestivum proteome. The Plant journal : for cell and molecular biology 89, 601-616, doi:10.1111/tpj.13402 (2017).

9. Delcour, J. A. et al. Wheat Gluten Functionality as a Quality Determinant in Cereal-Based Food Products. Annu Rev Food Sci T 3, 469-492, doi:10.1146/annurev-food-022811-101303 (2012).

10. Dominguez, F. \& Cejudo, F. J. Characterization of the Endoproteases Appearing during Wheat Grain Development. Plant physiology 112, 1211-1217, doi:10.1104/pp.112.3.1211 (1996).

11. Nadaud, I. et al. Proteomic and morphological analysis of early stages of wheat grain development. Proteomics 10, 2901-2910, doi:10.1002/pmic.200900792 (2010).

12. Rangan, P., Furtado, A. \& Henry, R. J. The transcriptome of the developing grain: a resource for understanding seed development and the molecular control of the functional and nutritional properties of wheat. BMC genomics 18, 766, doi:10.1186/s12864-017-4154-z (2017).

13. Pedrazzini, E., Mainieri, D., Marrano, C. A. \& Vitale, A. Where do Protein Bodies of Cereal Seeds Come From? Frontiers in plant science 7, 1139, doi:10.3389/fpls.2016.01139 (2016).

14. Tosi, P. et al. Trafficking of storage proteins in developing grain of wheat. Journal of experimental botany 60, 979-991, doi:10.1093/jxb/ern346 (2009).

15. Tahir, A. et al. Deciphering carbohydrate metabolism during wheat grain development via integrated transcriptome and proteome dynamics. Molecular biology reports 47, 5439-5449, doi:10.1007/s11033-020-05634-w (2020).

16. McLoughlin, F. et al. Maize multi-omics reveal roles for autophagic recycling in proteome remodelling and lipid turnover. Nat Plants 4, 1056-1070, doi:10.1038/s41477-018-0299-2 (2018).

17. Reich, S. et al. A multi-omics analysis reveals the unfolded protein response regulon and stress-induced resistance to folate-based antimetabolites. Nature communications 11, 2936, doi:10.1038/s41467-020-16747-y (2020).

18. Nelson, C. J. \& Millar, A. H. Protein turnover in plant biology. Nat Plants 1, doi:Artn 1501710.1038/Nplants.2015.17 (2015).

19. Li, L. et al. Protein Degradation Rate in Arabidopsis thaliana Leaf Growth and Development. The Plant cell 29, 207-228, doi:10.1105/tpc.16.00768 (2017).

20. Nelson, C. J., Li, L. \& Millar, A. H. Quantitative analysis of protein turnover in plants. Proteomics 14, 579-592, doi:10.1002/pmic.201300240 (2014). 
21. Fan, K. T. et al. Proteome Scale-Protein Turnover Analysis Using High Resolution Mass Spectrometric Data from Stable-Isotope Labeled Plants. Journal of proteome research 15, 851-867, doi:10.1021/acs.jproteome.5b00772 (2016).

22. Galland, M. et al. Dynamic proteomics emphasizes the importance of selective mRNA translation and protein turnover during Arabidopsis seed germination. Molecular \& cellular proteomics : MCP 13, 252-268, doi:10.1074/mcp.M113.032227 (2014).

23. Lyon, D. et al. Drought and Recovery: Independently Regulated Processes Highlighting the Importance of Protein Turnover Dynamics and Translational Regulation in Medicago truncatula. Molecular \& cellular proteomics : MCP 15, 1921-1937, doi:10.1074/mcp.M115.049205 (2016).

24. Martin, S. F., Munagapati, V. S., Salvo-Chirnside, E., Kerr, L. E. \& Le Bihan, T. Proteome turnover in the green alga Ostreococcus tauri by time course $15 \mathrm{~N}$ metabolic labeling mass spectrometry. Journal of proteome research 11, 476-486, doi:10.1021/pr2009302 (2012).

25. Yao, S. X., Zhang, Y., Chen, Y. L., Deng, H. T. \& Liu, J. Y. SILARS: an effective stable isotope labeling with ammonium nitrate-15N in rice seedlings for quantitative proteomic analysis. Molecular plant 7, 1697-1700, doi:10.1093/mp/ssu089 (2014).

26. Nelson, C. J., Alexova, R., Jacoby, R. P. \& Millar, A. H. Proteins with High Turnover Rate in Barley Leaves Estimated by Proteome Analysis Combined with in Planta Isotope Labeling. Plant physiology 166, 91-108, doi:10.1104/pp.114.243014 (2014).

27. Dawson, T. E., Mambelli, S., Plamboeck, A. H., Templer, P. H. \& Tu, K. P. Stable isotopes in plant ecology. Annu Rev Ecol Syst 33, 507-559, doi:10.1146/annurev.ecolsys.33.020602.095451 (2002).

28. Rogers, S. O. \& Quatrano, R. S. Morphological Staging of Wheat Caryopsis Development. Am J Bot 70, 308-311, doi:Doi 10.2307/2443277 (1983).

29. Fischer, W. N. et al. Amino acid transport in plants. Trends Plant Sci 3, 188-195, doi:Doi 10.1016/S1360-1385(98)01231-X (1998).

30. Thimm, O. et al. MAPMAN: a user-driven tool to display genomics data sets onto diagrams of metabolic pathways and other biological processes. Plant Journal 37, 914-939, doi:10.1111/j.1365-313X.2004.02016.x (2004).

31. Blum, A., Mayer, J. \& Golan, G. Chemical Desiccation of Wheat Plants as a Simulator of PostAnthesis Stress .2. Relations to Drought Stress. Field Crop Res 6, 149-155, doi:Doi 10.1016/0378-4290(83)90054-0 (1983).

32. Nelson, C. J., Li, L., Jacoby, R. P. \& Millar, A. H. Degradation Rate of Mitochondrial Proteins in Arabidopsis thaliana Cells. Journal of proteome research 12, 3449-3459, doi:10.1021/pr400304r (2013).

33. Hooper, C. M., Castleden, I. R., Aryamanesh, N., Jacoby, R. P. \& Millar, A. H. Finding the Subcellular Location of Barley, Wheat, Rice and Maize Proteins: The Compendium of Crop Proteins with Annotated Locations (cropPAL). Plant and Cell Physiology 57, doi:10.1093/pcp/pcv170 (2016).

34. Herman, E. M. \& Larkins, B. A. Protein storage bodies and vacuoles. The Plant cell 11, 601613, doi:DOI 10.1105/tpc.11.4.601 (1999).

35. Kaleta, C., Schauble, S., Rinas, U. \& Schuster, S. Metabolic costs of amino acid and protein production in Escherichia coli. Biotechnol J 8, 1105-1114, doi:10.1002/biot.201200267 (2013).

36. Peth, A., Nathan, J. A. \& Goldberg, A. L. The ATP Costs and Time Required to Degrade Ubiquitinated Proteins by the 26 S Proteasome. Journal of Biological Chemistry 288, 2921529222 (2013).

37. Piques, M. et al. Ribosome and transcript copy numbers, polysome occupancy and enzyme dynamics in Arabidopsis. Mol Syst Biol 5 (2009). 
38. Yang, X. Y. et al. Measuring the turnover rates of Arabidopsis proteins using deuterium oxide: an auxin signaling case study. Plant Journal 63, 680-695, doi:10.1111/j.1365313X.2010.04266.x (2010).

39. Flugge, U. I., Hausler, R. E., Ludewig, F. \& Gierth, M. The role of transporters in supplying energy to plant plastids. Journal of experimental botany 62, 2381-2392, doi:10.1093/jxb/erq361 (2011).

40. Jenner, C. F., Ugalde, T. D. \& Aspinall, D. The Physiology of Starch and Protein Deposition in the Endosperm of Wheat. Aust J Plant Physiol 18, 211-226, doi:Doi 10.1071/Pp9910211 (1991).

41. Keeling, P. L., Wood, J. R., Tyson, R. H. \& Bridges, I. G. Starch Biosynthesis in Developing Wheat-Grain - Evidence against the Direct Involvement of Triose Phosphates in the Metabolic Pathway. Plant physiology 87, 311-319, doi:DOI 10.1104/pp.87.2.311 (1988).

42. Zorb, C., Ludewig, U. \& Hawkesford, M. J. Perspective on Wheat Yield and Quality with Reduced Nitrogen Supply. Trends Plant Sci 23, 1029-1037, doi:10.1016/j.tplants.2018.08.012 (2018).

43. Barak, S., Mudgil, D. \& Khatkar, B. S. Influence of Gliadin and Glutenin Fractions on Rheological, Pasting, and Textural Properties of Dough. Int J Food Prop 17, 1428-1438, doi:10.1080/10942912.2012.717154 (2014).

44. Dhaka, V. \& Khatkar, B. S. Effects of Gliadin/Glutenin and Hmw-Gs/Lmw-Gs Ratio on Dough Rheological Properties and Bread-Making Potential of Wheat Varieties. J Food Quality 38, 7182, doi:10.1111/jfq.12122 (2015).

45. Geisslitz, S., Longin, C. F. H., Scherf, K. A. \& Koehler, P. Comparative Study on Gluten Protein Composition of Ancient (Einkorn, Emmer and Spelt) and Modern Wheat Species (Durum and Common Wheat). Foods 8, doi:10.3390/foods8090409 (2019).

46. Galili, G. et al. Assembly and Transport of Wheat Storage Proteins. Journal of plant physiology 145, 626-631, doi:Doi 10.1016/S0176-1617(11)81274-5 (1995).

47. Abreu, R. D., Penalva, L. O., Marcotte, E. M. \& Vogel, C. Global signatures of protein and mRNA expression levels. Molecular bioSystems 5, 1512-1526, doi:10.1039/b908315d (2009).

48. Zander, M. et al. Integrated multi-omics framework of the plant response to jasmonic acid. Nat Plants 6, 290-+, doi:10.1038/s41477-020-0605-7 (2020).

49. Brady, S. M. et al. A high-resolution root spatiotemporal map reveals dominant expression patterns. Science 318, 801-806, doi:10.1126/science.1146265 (2007).

50. Pfeifer, M. et al. Genome interplay in the grain transcriptome of hexaploid bread wheat. Science 345, 1250091, doi:10.1126/science.1250091 (2014).

51. Selkrig, J. et al. Spatiotemporal proteomics uncovers cathepsin-dependent macrophage cell death during Salmonella infection. Nat Microbiol, doi:10.1038/s41564-020-0736-7 (2020).

52. Munns, R. \& James, R. A. Screening methods for salinity tolerance: a case study with tetraploid wheat. Plant Soil 253, 201-218, doi:Doi 10.1023/A:1024553303144 (2003).

53. Scafaro, A. P. et al. The combination of gas-phase fluorophore technology and automation to enable high-throughput analysis of plant respiration. Plant Methods 13, 16, doi:10.1186/s13007-017-0169-3 (2017).

54. Wessel, D. \& Flugge, U. I. A Method for the Quantitative Recovery of Protein in DiluteSolution in the Presence of Detergents and Lipids. Analytical biochemistry 138, 141-143, doi:Doi 10.1016/0003-2697(84)90782-6 (1984).

55. Schaffner, W. \& Weissmann, C. A rapid, sensitive, and specific method for the determination of protein in dilute solution. Analytical biochemistry 56, 502-514, doi:10.1016/00032697(73)90217-0 (1973).

56. Wang, Y. et al. Reversed-phase chromatography with multiple fraction concatenation strategy for proteome profiling of human MCF10A cells. Proteomics 11, 2019-2026, doi:10.1002/pmic.201000722 (2011). 
57. Deutsch, E. W. et al. Trans-Proteomic Pipeline, a standardized data processing pipeline for large-scale reproducible proteomics informatics. Proteomics Clin App/ 9, 745-754, doi:10.1002/prca.201400164 (2015).

58. Appels, R. et al. Shifting the limits in wheat research and breeding using a fully annotated reference genome. Science 361, 661-+, doi:ARTN eaar719110.1126/science.aar7191 (2018).

59. Eng, J. K., Jahan, T. A. \& Hoopmann, M. R. Comet: an open-source MS/MS sequence database search tool. Proteomics 13, 22-24, doi:10.1002/pmic.201200439 (2013).

60. O'Leary, B. M. et al. Variation in Leaf Respiration Rates at Night Correlates with Carbohydrate and Amino Acid Supply. Plant physiology 174, 2261-2273, doi:10.1104/pp.17.00610 (2017).

61. Cox, J. \& Mann, M. MaxQuant enables high peptide identification rates, individualized p.p.b.range mass accuracies and proteome-wide protein quantification. Nat Biotechnol 26, 13671372, doi:10.1038/nbt.1511 (2008).

62. Tyanova, S., Temu, T. \& Cox, J. The MaxQuant computational platform for mass spectrometry-based shotgun proteomics. Nature protocols 11, 2301-2319, doi:10.1038/nprot.2016.136 (2016).

63. Kryuchkova-Mostacci, N. \& Robinson-Rechavi, M. A benchmark of gene expression tissuespecificity metrics. Brief Bioinform 18, 205-214, doi:10.1093/bib/bbw008 (2017).

64. Hamilton, N. E. \& Ferry, M. ggtern: Ternary Diagrams Using ggplot2. J Stat Softw 87, 1-17, doi:10.18637/jss.v087.c03 (2018).

65. Huo, N. et al. Gene Duplication and Evolution Dynamics in the Homeologous Regions Harboring Multiple Prolamin and Resistance Gene Families in Hexaploid Wheat. Frontiers in plant science 9, 673, doi:10.3389/fpls.2018.00673 (2018).

66. Huo, N. et al. Dynamic Evolution of alpha-Gliadin Prolamin Gene Family in Homeologous Genomes of Hexaploid Wheat. Scientific reports 8, 5181, doi:10.1038/s41598-018-23570-5 (2018).

67. Li, L., Nelson, J., Solheim, C., Whelan, J. \& Millar, A. H. Determining degradation and synthesis rates of arabidopsis proteins using the kinetics of progressive $15 \mathrm{~N}$ labeling of twodimensional gel-separated protein spots. Molecular \& cellular proteomics : MCP 11, M111.010025, doi:10.1074/mcp.M111.010025 (2012).

68. Borrill, P., Ramirez-Gonzalez, R. \& Uauy, C. expVIP: a Customizable RNA-seq Data Analysis and Visualization Platform. Plant physiology 170, 2172-2186, doi:10.1104/pp.15.01667 (2016).

69. Ramirez-Gonzalez, R. H. et al. The transcriptional landscape of polyploid wheat. Science 361, doi:10.1126/science.aar6089 (2018). 
709 H.C was supported by Research Training Program Fee Offset - International Student and UWA

710 Safety-Net Top-Up Scholarships. This work was supported by Australian Research Council funding to

711 A.H.M (CE140100008; FL200100057)

712 Author contributions

713 H.C, O.D and A.H.M conceived and designed the project. H.C and O.D performed the experiment and

714 data analysis. H.C wrote the manuscript, A.H.M and O.D read and corrected the manuscript.

\section{Competing interests}

716 The authors declare no competing interests 

stages. $\mathbf{b}$, The fresh weight of individual grain at different developmental stages $(n=64)$. $\mathbf{c}$, The ${ }^{15} \mathrm{~N}$ enrichment in newly synthesised proteins at 10, 14 and 17DPA after a switch to ${ }^{15} \mathrm{~N}$ media at 7DPA. d, Respiration rate $\left(R_{N}\right)$ of wheat grain at different developmental stages expressed as $\mathrm{O}_{2}$ consumption rate $\left(\mathrm{nmol} \mathrm{O}_{2}\right.$ per gram fresh weight per second; $\left.n=64\right)$. Detailed data used in this analysis are listed in Supplementary Data 1.

Fig. 2. | Fold change in abundance (FCP) of 2307 proteins during wheat grain development. a, in abundance $\geq 2$ or $\leq 0.5$ and with a $p$-value $\leq 0.05$ are shown by red circles (increase abundance) or blue circles (decrease abundance), respectively. All other data points are show as black circles. The number of proteins of each colour is shown on the top-left corner of each plot, and dashed lines indicate the cut-off value of fold change in protein abundance and p-value. $\mathbf{b}$, Examples of slow FCP of ribosomal proteins compared to the rapid accumulation of storage proteins during grain development. c, Proteins with fold change in abundance between 7DPA and 17DPA are shown in 34 functional categories ( $\geq 10$ proteins) within 7 broad functional categories. Proteins in all other categories ( $\leq 10$ proteins per category) are grouped into the 'Others' category. The number of proteins in each category is displayed along with $x$-axis, and functional categories were sorted within each super category by increasing median FCP. The y-axis is log2 transformed FCP and the dashed line shows the overall median FCP across all wheat grain proteins. Pairwise t-test results between categories are listed on Supplementary Data 4b. Broad functional categories are: Amino acid metabolism (Green), Carbohydrate metabolism (Orange-red), Nucleotide metabolism (Purple), Lipid metabolism (Pink), Energy producing (Lawngreen), Stress response (Gold) and 'Other' categories (Black). 
Fig. 3. | Rates of synthesis and degradation of $\mathbf{1 4 4 7}$ wheat grain proteins during grain development.

a, The averaged protein synthesis $\left(K_{S} / A\right)$ and degradation $\left(K_{D}\right)$ rates calculated across all three time points grouped by the subcellular location of each protein (CropPAL.org). The major subcellular locations highlighted are Mitochondria (Mt, Pink), Cytosol (Cyt, Green), Plastid (Pt, Lawngreen), grouped by both subcellular location and functional category. Only major functional categories with protein no. $\geq 10$ were displayed, and minor categories with protein no. $<10$ were grouped into 'Others'. The colour scheme was the same used in a. c, Examples of 6 functional categories of interest showing the largest difference (upper panel) and smallest difference (lower panel) between $\mathrm{K}_{\mathrm{S}} / \mathrm{A}$ and $\mathrm{K}_{\mathrm{D}}$ at each time point. Detailed statistical analysis is explained, and relevant results are listed in Supplementary Data $5 c$.

Fig. 4. I Changes in protein abundance and protein synthesis and degradation rate profiles of proteins expressed in different grain tissue types during grain development. a, A ternary plot of the abundances of 5550 protein groups measured in Endosperm, Embryo and Pericarp extracts from grain. Each circle represents a protein and its position indicates the relative contribution of each protein to grain tissue in grain protein abundance. Proteins with a relative contribution $\geq 66 \%$ in one tissue and a protein concentration $\geq 3$-fold that in the other two tissues are defined as tissue-specific proteins (shown close to triangle vertices), proteins with a relative contribution $\leq 17 \%$ in one tissue are defined as tissue-suppressed proteins (between vertices and close to edges), while the remaining proteins are found relatively evenly balanced across grain tissues (grey circles in the middle). $\mathbf{b}$, Box plots of the relative protein contribution (upper panel) and actual relative abundance estimated via label free quantification (lower panel) for each tissue in each protein expression category. c, Line plots showing FCP (Blue), protein synthesis rate (Orange) and protein degradation rate (Green) of balanced and 
tissue specific protein sets during grain development. Only proteins having values (FCP or turnover rates) at all three time points are included. The dashed line demonstrates the mean values, and the grey shade area shows the $95 \%$ confidence intervals. The optimized y-axis scale version are inserted for embryo and pericarp specific proteins to highlight the change pattern.

Fig. 5. | ATP energy budget used in wheat grain proteome synthesis and maintenance during grain

development. a, The overall proportion of cellular ATP budget used for protein synthesis, protein degradation, and other cell events and maintenance. $\mathbf{b}$, proportional distributions of protein copy numbers (iBAQ) and ATP cost of protein building and maintenance of major cellular organelles and subcellular structures. Proteins in location groups sorted by decreasing ATP usage for protein synthesis. The number of proteins in each category is included within brackets. c, proportional distributions of protein copy numbers (iBAQ) and ATP cost of protein building and maintenance of protein in major functional categories. $\mathbf{d}$, Bubble plots showing, by the size of circles, the changing profiles of cellular ATP energy budget for different classes of proteins during grain development. The top three functional categories having both fast $K_{S} / A$ and $K_{D}$ rates (Orange-red), fast $K_{S} / A$ and slow $K_{D}$ rates (Violet-red), and both slow $K_{S} / A$ and $K_{D}$ rates (Blue) are highlighted. Calculations are based on grain total ATP production in a, but based on total ATP energy budget for protein synthesis or degradation in $\mathbf{b}, \mathbf{c}$ and

d.

Fig. 6. I Accumulation profiles of key storage protein families during grain filling. a, The example radar chart. Six categories of data were collected and analysed, namely transcript data (mRNA, rang: 0-1000 tpm), fold change in protein abundance (FCP, rang: 1-25 folds), protein synthesis rate $\left(\mathrm{K}_{\mathrm{S}} / \mathrm{A}_{\text {, }}\right.$ rang: 0-5.84 $\mathrm{d}^{-1}$ ), ATP energy cost for protein synthesis (CostSyn, rang: 0-290.2 nmol ATP mcopy ${ }^{-1}$ grain $^{-}$

$\left.{ }^{1} \mathrm{~d}^{-1}\right)$, protein degradation rate $\left(K_{D}\right.$, rang: $\left.0-1.36 \mathrm{~d}^{-1}\right)$, and ATP energy cost for protein degradation 
bioRxiv preprint doi: https://doi.org/10.1101/2021.06.15.448508; this version posted June 15, 2021. The copyright holder for this preprint

(which was not certified by peer review) is the author/funder, who has granted bioRxiv a license to display the preprint in perpetuity. It is made available under aCC-BY-NC-ND 4.0 International license.

between protein types. The raw data and statistical test results are collected at Supplementary Data

795

8. b, Radar charts showing the six molecular profiles of the key wheat grain storage proteins at 10,14 ,

796 and 17DPA during grain filling. c, Abundance of the key wheat grain storage proteins at 17DPA.

797 
Figures
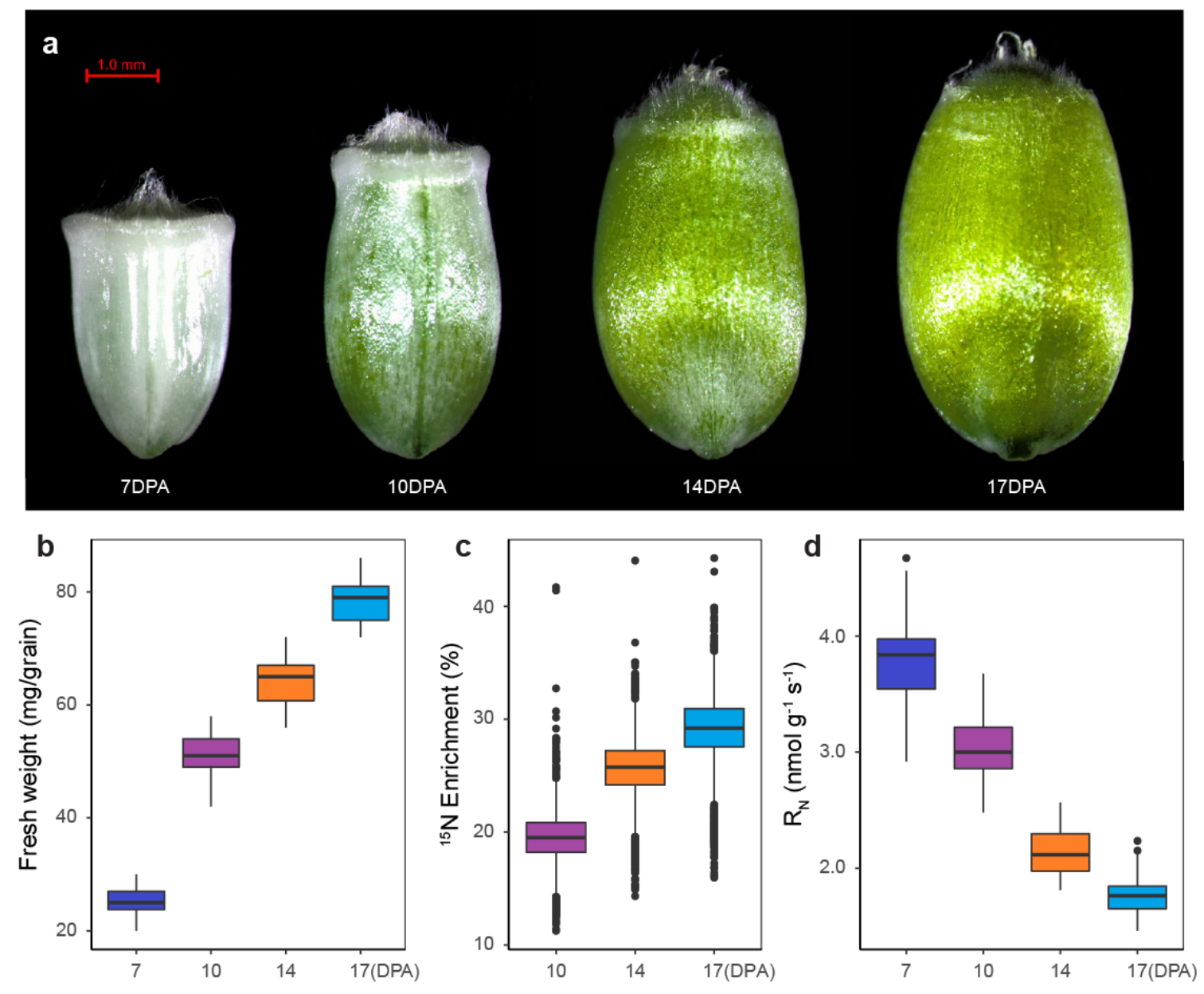

Fig. 1. | Time-dependent changes in grain size, fresh weight, respiration rate and ${ }^{15} \mathrm{~N}$ labelling of newly synthesised protein. a, A representative image of wheat grain at different developmental stages. b, The fresh weight of individual grain at different developmental stages $(n=64)$. c, The ${ }^{15} \mathrm{~N}$ enrichment in newly synthesised proteins at 10,14 and 17DPA after a switch to ${ }^{15} \mathrm{~N}$ media at 7DPA. $d$, Respiration rate $\left(R_{N}\right)$ of wheat grain at different developmental stages expressed as $\mathrm{O}_{2}$ consumption rate $\left(\mathrm{nmol} \mathrm{O}_{2}\right.$ per gram fresh weight per second; $\left.n=64\right)$. Detailed data used in this analysis are listed in Supplementary Data 1. 

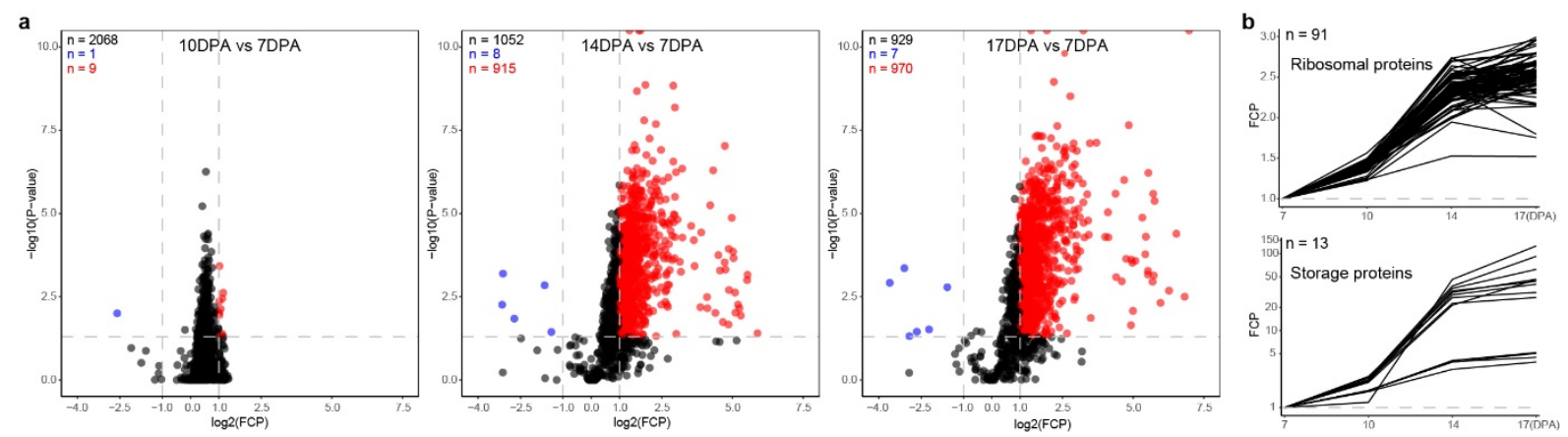

c
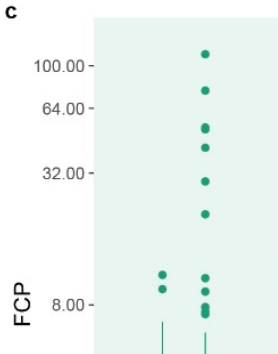

Fig. 2. | Fold change in abundance (FCP) of 2307 proteins during wheat grain development. a, Volcano plots of all fold changes in protein abundance at each time point. Proteins with a fold change in abundance $\geq 2$ or $\leq 0.5$ and with a $p$-value $\leq 0.05$ are shown by red circles (increase abundance) or blue circles (decrease abundance), respectively. All other data points are show as black circles. The number of proteins of each colour is shown on the top-left corner of each plot, and dashed lines indicate the cut-off value of fold change in protein abundance and $p$-value. $\mathbf{b}$, Examples of slow FCP of ribosomal proteins compared to the rapid accumulation of storage proteins during grain development. c, Proteins with fold change in abundance between 7DPA and 17DPA are shown in 34 functional categories ( $\geq 10$ proteins) within 7 broad functional categories. Proteins in all other categories ( $\leq 10$ proteins per category) are grouped into the 'Others' category. The number of proteins in each category is displayed along with $x$-axis, and functional categories were sorted within each super category by increasing median FCP. The $y$-axis is log2 transformed FCP and the dashed line shows the overall median FCP across all wheat grain proteins. Pairwise t-test results between categories are listed on Supplementary Data 4b. Broad functional categories are: Amino acid metabolism (Green), Carbohydrate metabolism (Orange-red), Nucleotide metabolism (Purple), Lipid metabolism (Pink), Energy producing (Lawngreen), Stress response (Gold) and 'Other' categories (Black). 

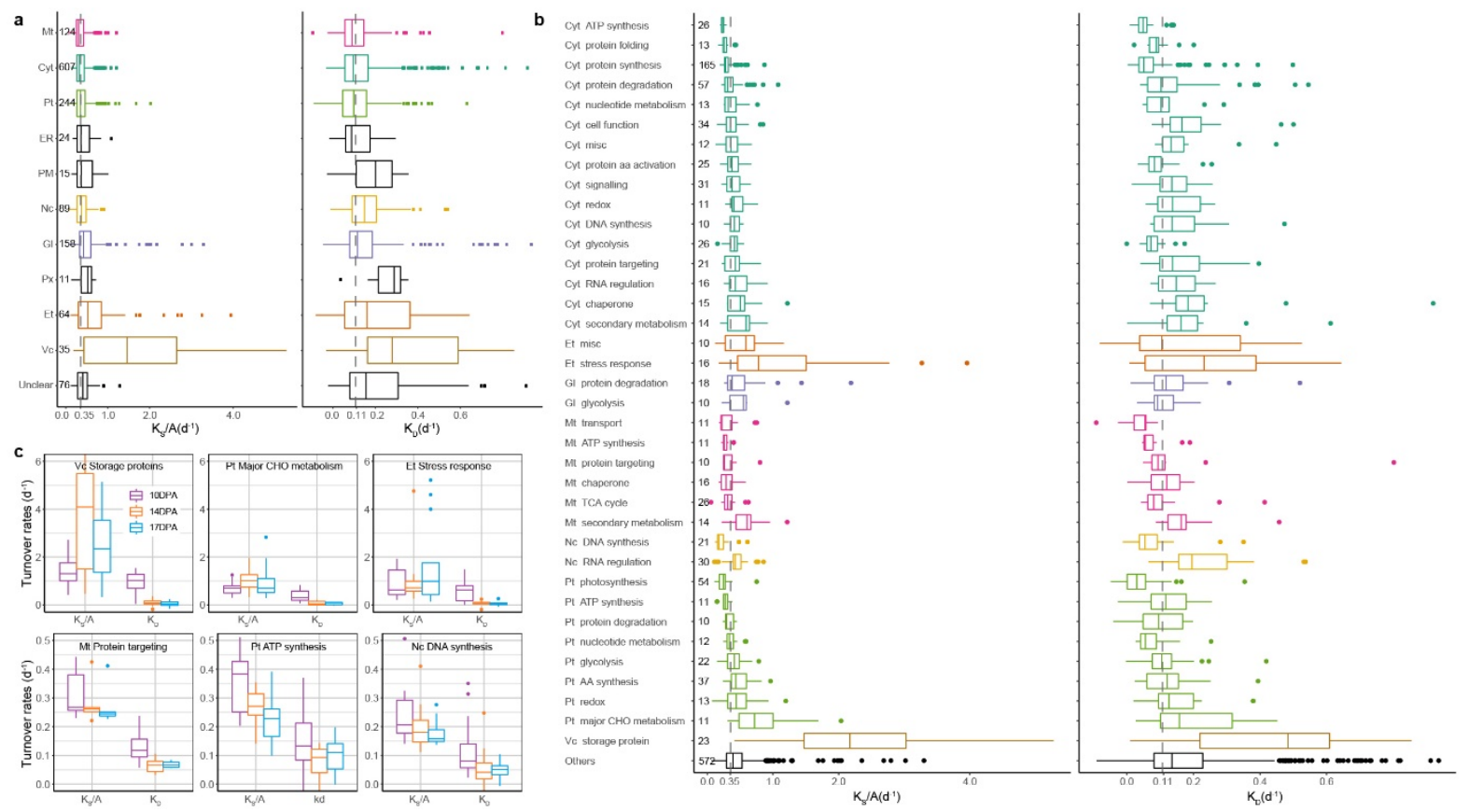

Fig. 3. | Rates of synthesis and degradation of $\mathbf{1 4 4 7}$ wheat grain proteins during grain development.

a, The averaged protein synthesis $\left(K_{S} / A\right)$ and degradation $\left(K_{D}\right)$ rates calculated across all three time points grouped by the subcellular location of each protein (CropPAL.org). The major subcellular locations highlighted are Mitochondria (Mt, Pink), Cytosol (Cyt, Green), Plastid (Pt, Lawngreen), Nucleus (Nc, Gold), Golgi Apparatus (GI, Purple), Extracellular (Et, Orange-red), and Vacuole (Vc, Peru). Dashed lines indicate the overall median $K_{S} / A$ and $K_{D}$ across all proteins. The number of proteins in each subcellular location is displayed next to the $y$-axis. Boxes are sorted by increasing order of median $\mathrm{K}_{\mathrm{S}} / \mathrm{A}$. $\mathbf{b}$, The averaged protein synthesis and degradation rates calculated across the three time points grouped by both subcellular location and functional category. Only major functional categories with protein no. $\geq 10$ were displayed, and minor categories with protein no. $<10$ were grouped into 'Others'. The colour scheme was the same used in a. c, Examples of 6 functional categories of interest showing the largest difference (upper panel) and smallest difference (lower panel) between $\mathrm{K}_{\mathrm{S}} / \mathrm{A}$ and $\mathrm{K}_{\mathrm{D}}$ at each time point. Detailed statistical analysis is explained, and relevant results are listed in Supplementary Data $5 c$. 
a

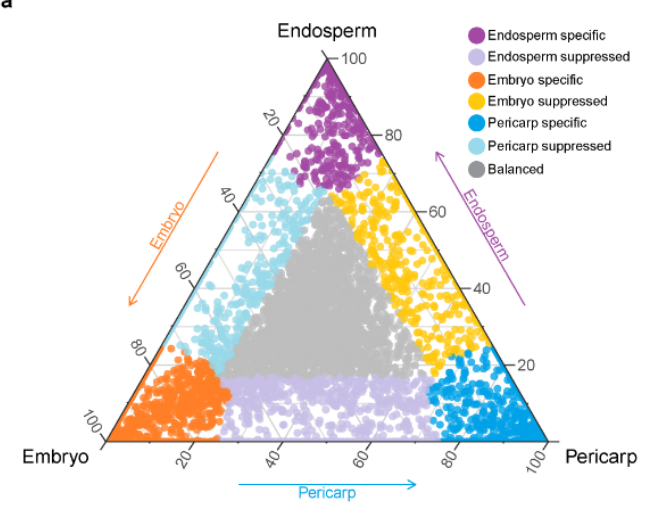

b
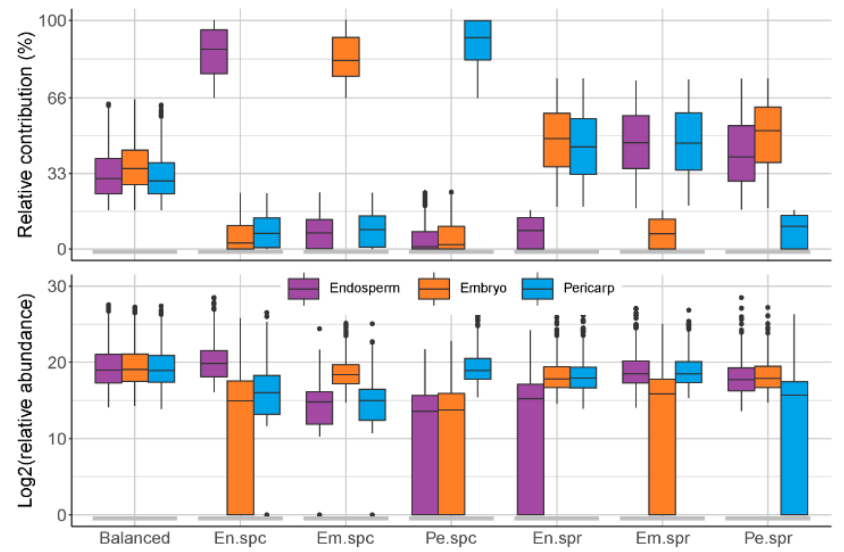
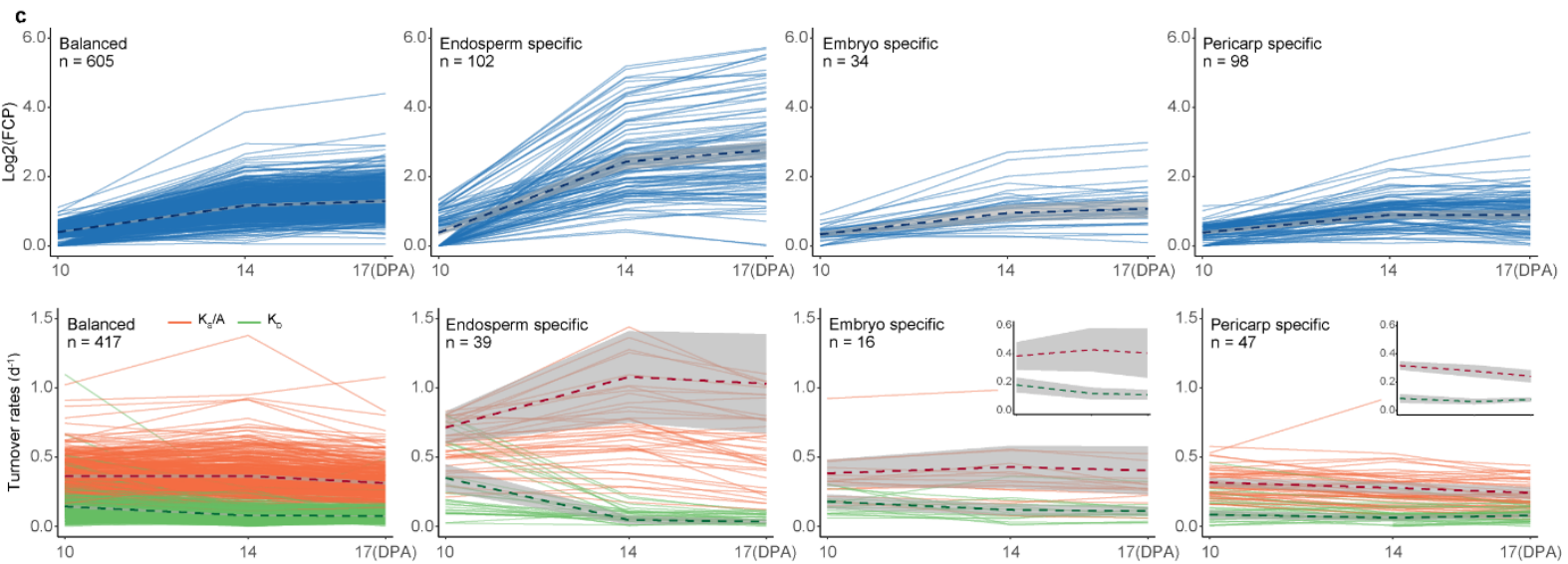

Fig. 4. I Changes in protein abundance and protein synthesis and degradation rate profiles of proteins expressed in different grain tissue types during grain development. a, A ternary plot of the abundances of 5550 protein groups measured in Endosperm, Embryo and Pericarp extracts from grain. Each circle represents a protein and its position indicates the relative contribution of each protein to grain tissue in grain protein abundance. Proteins with a relative contribution $\geq 66 \%$ in one tissue and a protein concentration $\geq 3$-fold that in the other two tissues are defined as tissue-specific proteins (shown close to triangle vertices), proteins with a relative contribution $\leq 17 \%$ in one tissue are defined as tissue-suppressed proteins (between vertices and close to edges), while the remaining proteins are found relatively evenly balanced across grain tissues (grey circles in the middle). $\mathbf{b}$, Box plots of the relative protein contribution (upper panel) and actual relative abundance estimated via label free quantification (lower panel) for each tissue in each protein expression category. c, Line plots showing FCP (Blue), protein synthesis rate (Orange) and protein degradation rate (Green) of balanced and tissue specific protein sets during grain development. Only proteins having values (FCP or turnover rates) at all three time points are included. The dashed line demonstrates the mean values, and the grey shade area shows the $95 \%$ confidence intervals. The optimized $y$-axis scale version are inserted for embryo and pericarp specific proteins to highlight the change pattern. 

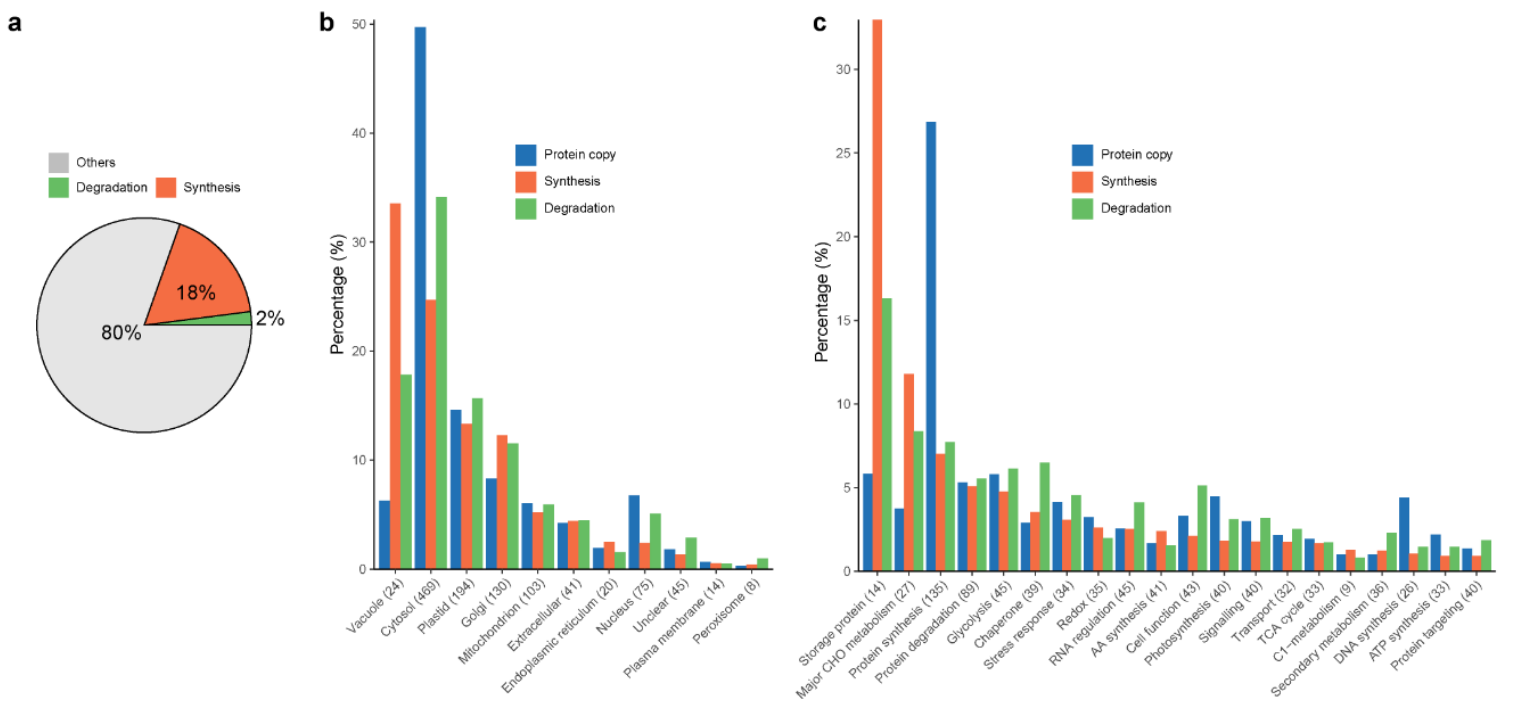

d
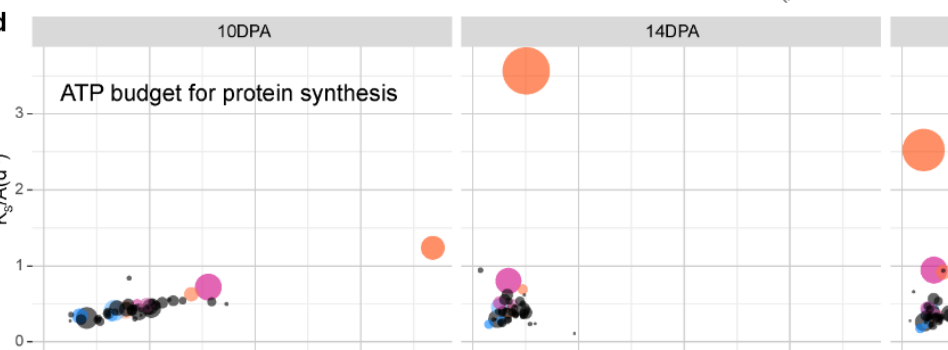

17DPA
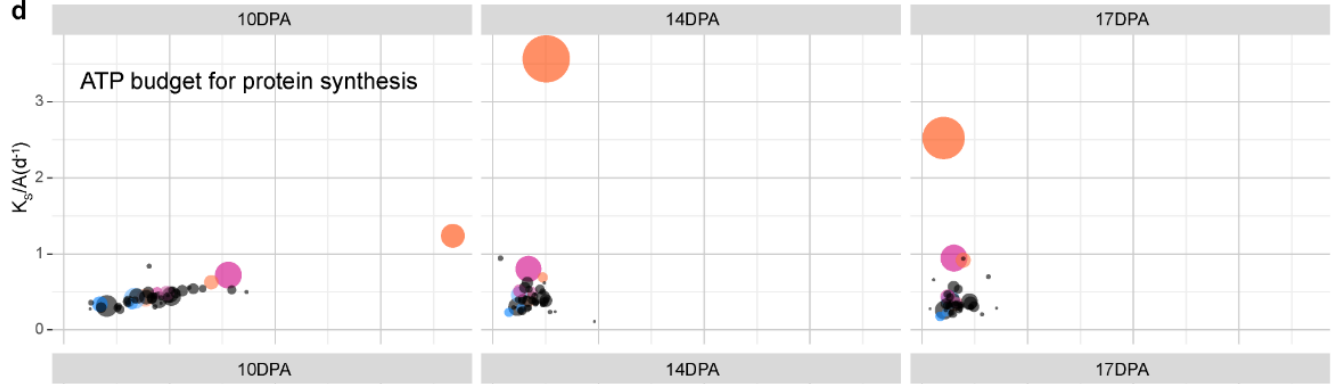

Functional Category Storage protein
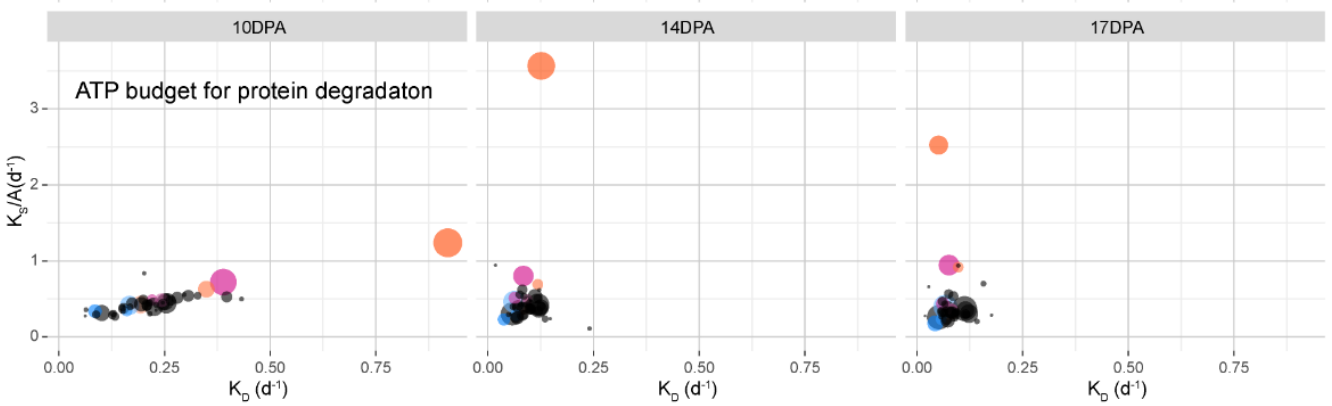

Percentage (\%)

Fig. 5. | ATP energy budget used in wheat grain proteome synthesis and maintenance during grain development. a, The overall proportion of cellular ATP budget used for protein synthesis, protein degradation, and other cell events and maintenance. $\mathbf{b}$, proportional distributions of protein copy numbers ( $\mathrm{B} B \mathrm{AQ}$ ) and ATP cost of protein building and maintenance of major cellular organelles and subcellular structures. Proteins in location groups sorted by decreasing ATP usage for protein synthesis. The number of proteins in each category is included within brackets. c, proportional distributions of protein copy numbers (iBAQ) and ATP cost of protein building and maintenance of protein in major functional categories. d, Bubble plots showing, by the size of circles, the changing profiles of cellular ATP energy budget for different classes of proteins during grain development. The top three functional categories having both fast $K_{S} / A$ and $K_{D}$ rates (Orange-red), fast $K_{S} / A$ and slow $K_{D}$ rates (Violet-red), and both slow $K_{S} / A$ and $K_{D}$ rates (Blue) are highlighted. Calculations are based on grain total ATP production in a, but based on total ATP energy budget for protein synthesis or degradation in $\mathbf{b}, \mathbf{c}$ and d. 
a

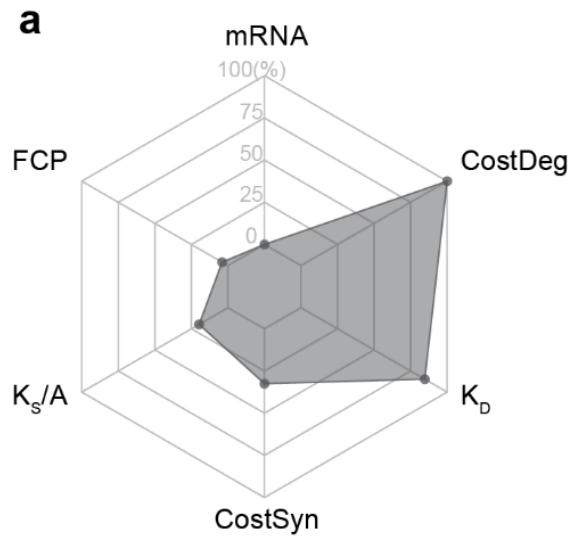

CostSyn

C

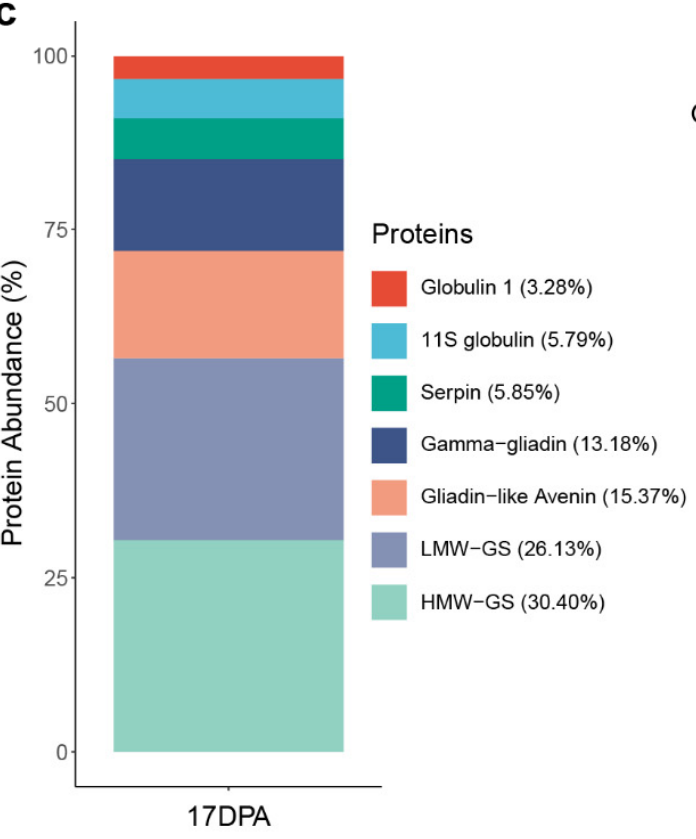

b

HMW-GS

10DPA

Gamma-gliadin
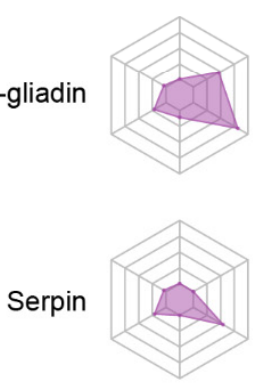

11 S Globulin

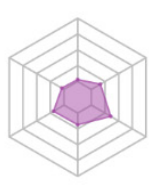

Globulin 1

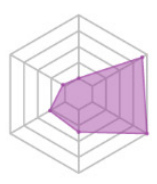

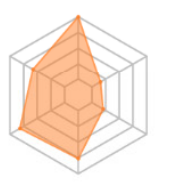
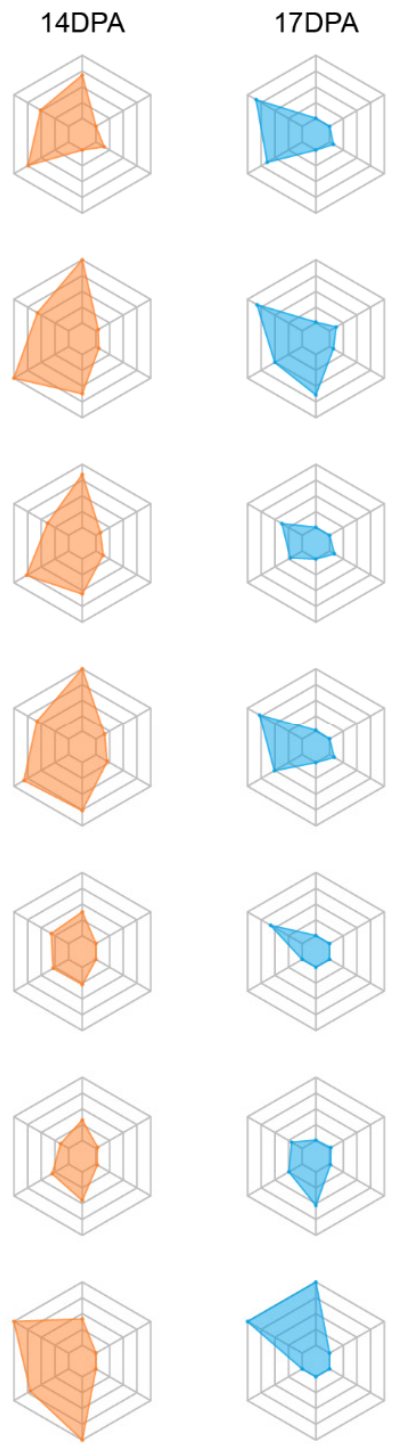

879

Fig. 6. | Accumulation profiles of key storage proteins during grain filling. a, The example radar chart.

Six categories of data were collected and analysed, namely transcript data (mRNA, rang: 0-1000 tpm), fold change in protein abundance (FCP, rang: 1-25 folds), protein synthesis rate ( $\mathrm{K}_{\mathrm{s}} / \mathrm{A}$, rang: 0-5.84 $\mathrm{d}^{-}$ ${ }^{1}$ ), ATP energy cost for protein synthesis (CostSyn, rang: 0-290.2 nmol ATP mcopy ${ }^{-1}$ grain $^{-1} \mathrm{~d}^{-1}$ ), protein degradation rate $\left(\mathrm{K}_{\mathrm{D}}\right.$, rang: 0-1.36 $\left.\mathrm{d}^{-1}\right)$, and ATP energy cost for protein degradation (CostDeg, rang: 0-

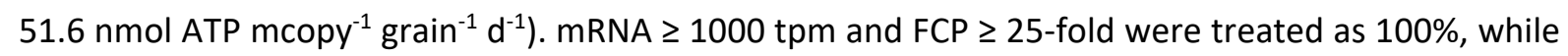
missing values were replaced by 0 for visualization. The percentage normalisation was conducted across all proteins and time points allows comparisons to be made in time series and between protein types. The raw data and statistical test results are collected at Supplementary Data 8. $\mathbf{b}$, Radar charts showing the six molecular profiles of the key wheat grain storage proteins at 10,14, and 17DPA during grain filling. $\mathbf{c}$, Abundance of the key wheat grain storage proteins at 17DPA. 
bioRxiv preprint doi: https://doi.org/10.1101/2021.06.15.448508; this version posted June 15, 2021. The copyright holder for this preprint (which was not certified by peer review) is the author/funder, who has granted bioRxiv a license to display the preprint in perpetuity. It is made available under aCC-BY-NC-ND 4.0 International license.

Extended Data Tables

Extended Data Table 1. The 20 most rapidly synthesized and degraded wheat grain proteins during grain development.

\begin{tabular}{|c|c|c|c|c|c|c|c|c|}
\hline Accession & Protein Name & Location & Functional Category & $\begin{array}{c}\text { Rates } \\
\left(d^{-1}\right)\end{array}$ & $\begin{array}{c}\text { Brep } \\
\text { No. }\end{array}$ & $\begin{array}{l}\text { Pep } \\
\text { No. }\end{array}$ & $\begin{array}{c}\text { Spectra } \\
\text { No. }\end{array}$ & $\begin{array}{c}\text { Half-Life } \\
\text { (d) }\end{array}$ \\
\hline \multicolumn{9}{|c|}{20 most rapidly synthesized proteins } \\
\hline TraesCS1D01G000300.1 & LMW-GS & vacuole & storage protein & 5.27 & 5 & 8 & 15 & NA \\
\hline TraesCS1A01G007400.1 & Gamma-gliadin & vacuole & storage protein & 4.37 & 7 & 7 & 19 & NA \\
\hline TraesCS1D01G000200.1 & LMW-GS & vacuole & storage protein & 4.27 & 6 & 8 & 30 & NA \\
\hline TraesCS1A01G066100.1 & Globulin-11S & vacuole & storage protein & 4.22 & 6 & 27 & 49 & NA \\
\hline TraesCS7B01G072000.1 & Alpah-Al & extracellular & stress response & 3.96 & 7 & 8 & 11 & NA \\
\hline TraesCS1B01G084300.1 & Globulin-11S & vacuole & storage protein & 3.41 & 6 & 13 & 21 & NA \\
\hline TraesCS3A01G095600.1 & Alpha-Al & golgi & stress response & 3.3 & 4 & 4 & 8 & NA \\
\hline TraesCS4B01G328000.1 & Alpah-Al & extracellular & stress response & 3.27 & 4 & 6 & 8 & NA \\
\hline TraesCS1B01G330000.1 & HMW-GS & vacuole & storage protein & 3.16 & 7 & 21 & 32 & NA \\
\hline TraesCS5A01G554200.1 & Beta-amylase & golgi & major $\mathrm{CHO}$ metabolism & 3.02 & 6 & 14 & 21 & NA \\
\hline TraesCS7D01G031700.1 & Gliadin-like avenin & vacuole & storage protein & 2.89 & 6 & 14 & 32 & NA \\
\hline TraesCS4A01G296000.1 & Globulin 1 & vacuole & storage protein & 2.85 & 4 & 6 & 8 & NA \\
\hline TraesCS1A01G007700.1 & Gamma-gliadin & vacuole & storage protein & 2.84 & 3 & 5 & 12 & NA \\
\hline TraesCSU01G032700.1 & Beta-amylase & golgi & major $\mathrm{CHO}$ metabolism & 2.8 & 8 & 44 & 92 & NA \\
\hline TraesCS4D01G325000.1 & Alpah-Al & extracellular & stress response & 2.77 & 4 & 8 & 22 & NA \\
\hline TraesCSU01G103300.1 & Peroxidase & extracellular & redox & 2.69 & 5 & 13 & 21 & NA \\
\hline TraesCS1B01G013500.1 & LMW-GS & vacuole & storage protein & 2.46 & 5 & 7 & 13 & NA \\
\hline TraesCS4A01G112300.1 & GILT & extracellular & not assigned & 2.35 & 5 & 16 & 27 & NA \\
\hline TraesCS1D01G317300.1 & HMW-GS & vacuole & storage protein & 2.21 & 3 & 4 & 5 & NA \\
\hline TraesCS6D01G356600.1 & Aspartic proteinase & golgi & protein degradation & 2.19 & 9 & 37 & 57 & NA \\
\hline \multicolumn{9}{|c|}{20 most rapidly degraded proteins } \\
\hline TraesCS6D01G000200.1 & Alpha-Al & golgi & stress response & 0.94 & 3 & 11 & 16 & 0.74 \\
\hline TraesCS4D01G212300.1 & HSP & cytosol & chaperone & 0.92 & 3 & 3 & 4 & 0.75 \\
\hline TraesCS2A01G310300.2 & SBE & NA & major $\mathrm{CHO}$ metabolism & 0.91 & 3 & 4 & 4 & 0.76 \\
\hline TraesCS7A01G035600.1 & Gamma-gliadin & vacuole & storage protein & 0.85 & 3 & 3 & 4 & 0.81 \\
\hline TraesCS6D01G089200.1 & Endoglucanase & golgi & misc & 0.82 & 4 & 9 & 10 & 0.84 \\
\hline TraesCS6D01G230000.1 & SAM & cytosol & AA synthesis & 0.82 & 3 & 13 & 16 & 0.85 \\
\hline TraesCS1A01G033600.1 & TIM17 & mitochondrion & protein targeting & 0.8 & 3 & 6 & 11 & 0.86 \\
\hline TraesCS7D01G307500.1 & UGE & golgi & cell wall relative & 0.78 & 3 & 4 & 6 & 0.89 \\
\hline TraesCS4A01G250800.1 & ERO1 & golgi & protein targeting & 0.77 & 3 & 11 & 13 & 0.9 \\
\hline TraesCS7D01G031700.1 & Gliadin-like avenin & vacuole & storage protein & 0.74 & 6 & 14 & 32 & 0.94 \\
\hline TraesCS4D01G252100.1 & Beta-xylosidase & golgi & cell wall relative & 0.73 & 3 & 6 & 7 & 0.94 \\
\hline TraesCS4A01G406200.1 & $\mathrm{ADH}$ & cytosol & fermentation & 0.73 & 3 & 9 & 9 & 0.95 \\
\hline TraesCS5D01G135900.1 & UTase & NA & AA metabolism & 0.72 & 3 & 4 & 5 & 0.97 \\
\hline TraesCS4D01G250000.1 & Alpha-Al & golgi & stress response & 0.71 & 3 & 12 & 16 & 0.98 \\
\hline TraesCS1D01G001000.1 & Gamma-gliadin & NA & storage protein & 0.7 & 5 & 5 & 6 & 0.99 \\
\hline TraesCS5D01G004000.1 & GSP & golgi & storage protein & 0.69 & 3 & 4 & 6 & 1 \\
\hline TraesCS7D01G364600.1 & ABA receptor & cytosol & stress response & 0.69 & 3 & 4 & 4 & 1.01 \\
\hline TraesCS5D01G210000.1 & TPS & cytosol & minor $\mathrm{CHO}$ metabolism & 0.68 & 3 & 5 & 5 & 1.01 \\
\hline TraesCS1A01G007400.1 & Gamma-gliadin & vacuole & storage protein & 0.68 & 7 & 7 & 19 & 1.02 \\
\hline TraesCS7D01G031800.1 & Gliadin-like avenin & vacuole & storage protein & 0.67 & 4 & 9 & 24 & 1.04 \\
\hline
\end{tabular}

The first wheat genome Traes ID number of the protein group, short protein name, subcellular location (from cropPAL.org) and functional category (MapMan) are included. The number of biological replicates (Brep No.), number of unique peptides (Pep No.) and number of mass spectra hits (Spectra No.) for each protein are also shown. 
bioRxiv preprint doi: https://doi.org/10.1101/2021.06.15.448508; this version posted June 15, 2021. The copyright holder for this preprint (which was not certified by peer review) is the author/funder, who has granted bioRxiv a license to display the preprint in perpetuity. It is made available under aCC-BY-NC-ND 4.0 International license.

Extended Data Table 2. The $\mathbf{2 0}$ wheat grain proteins with the highest ATP cost for biogenesis and maintenance during grain development.

\begin{tabular}{|c|c|c|c|c|c|c|c|c|}
\hline Accession & Protein Name & Location & Functional Category & $\begin{array}{l}\text { ATP Cost }(\mu \mathrm{mol} \\
\left.\text { grain }^{-1} \mathrm{~d}^{-1}\right)\end{array}$ & $\begin{array}{l}\text { ATP Cost } \\
(\%)\end{array}$ & $\begin{array}{l}\text { Brep } \\
\text { No. }\end{array}$ & $\begin{array}{l}\text { Pep } \\
\text { No. }\end{array}$ & $\begin{array}{c}\text { Spectra } \\
\text { No. }\end{array}$ \\
\hline \multicolumn{9}{|c|}{20 highest ATP cost proteins based on protein synthesis } \\
\hline TraesCS1A01G066100.1 & Globulin-11S & vacuole & storage protein & 0.928 & 1.663 & 6 & 27 & 49 \\
\hline TraesCS1B01G013500.1 & LMW-GS & vacuole & storage protein & 0.752 & 1.348 & 5 & 7 & 13 \\
\hline TraesCS7D01G031700.1 & Gliadin-like avenin & vacuole & storage protein & 0.546 & 0.979 & 6 & 14 & 32 \\
\hline TraesCS1D01G067100.1 & Globulin-11S & vacuole & storage protein & 0.337 & 0.604 & 5 & 13 & 25 \\
\hline TraesCS5A01G554200.1 & Beta-amylase & golgi & major $\mathrm{CHO}$ metabolism & 0.271 & 0.485 & 6 & 14 & 21 \\
\hline TraesCS2A01G168200.1 & Susy & cytosol & major $\mathrm{CHO}$ metabolism & 0.256 & 0.46 & 9 & 144 & 358 \\
\hline TraesCS1A01G007400.1 & Gamma-gliadin & vacuole & storage protein & 0.227 & 0.406 & 7 & 7 & 19 \\
\hline TraesCSU01G032700.1 & Beta-amylase & golgi & major $\mathrm{CHO}$ metabolism & 0.167 & 0.3 & 8 & 44 & 92 \\
\hline TraesCS4A01G296000.1 & Globulin 1 & vacuole & storage protein & 0.167 & 0.299 & 4 & 6 & 8 \\
\hline TraesCS1B01G449700.1 & AGPase & plastid & major $\mathrm{CHO}$ metabolism & 0.145 & 0.259 & 7 & 73 & 121 \\
\hline TraesCS4A01G214200.1 & PDI & endoplasmic reticulum & redox & 0.119 & 0.213 & 9 & 214 & 400 \\
\hline TraesCS7B01G072000.1 & Alpah-Al & extracellular & stress response & 0.119 & 0.213 & 7 & 8 & 11 \\
\hline TraesCS5D01G368900.1 & Serpin & golgi & protein degradation & 0.111 & 0.199 & 3 & 14 & 20 \\
\hline TraesCS1B01G330000.1 & HMW-GS & vacuole & storage protein & 0.107 & 0.192 & 7 & 21 & 32 \\
\hline TraesCS4D01G192900.1 & GILT & extracellular & not assigned & 0.102 & 0.183 & 6 & 8 & 10 \\
\hline TraesCS6A01G372500.1 & Aspartic proteinase & golgi & protein degradation & 0.096 & 0.172 & 5 & 9 & 12 \\
\hline TraesCS7D01G284900.2 & AGPase & plastid & major $\mathrm{CHO}$ metabolism & 0.094 & 0.168 & 4 & 4 & 5 \\
\hline TraesCS1B01G102700.1 & Aminotransferase & plastid & AA synthesis & 0.094 & 0.168 & 9 & 114 & 175 \\
\hline TraesCS7D01G535400.1 & SBE & plastid & major $\mathrm{CHO}$ metabolism & 0.088 & 0.158 & 4 & 11 & 11 \\
\hline TraesCS7D01G031800.1 & Gliadin-like avenin & vacuole & storage protein & 0.079 & 0.142 & 4 & 9 & 24 \\
\hline \multicolumn{9}{|c|}{20 highest ATP cost proteins based on protein degradation } \\
\hline TraesCS1B01G330000.1 & HMW-GS & vacuole & storage protein & 0.0585 & 0.105 & 7 & 21 & 32 \\
\hline TraesCS7D01G031800.1 & Gliadin-like avenin & vacuole & storage protein & 0.0433 & 0.078 & 4 & 9 & 24 \\
\hline TraesCS1B01G449700.1 & AGPase & plastid & major $\mathrm{CHO}$ metabolism & 0.0244 & 0.044 & 7 & 73 & 121 \\
\hline TraesCS5A01G554200.1 & Beta-amylase & golgi & major $\mathrm{CHO}$ metabolism & 0.0242 & 0.043 & 6 & 14 & 21 \\
\hline TraesCS1B01G013500.1 & LMW-GS & vacuole & storage protein & 0.0236 & 0.042 & 5 & 7 & 13 \\
\hline TraesCS1A01G007400.1 & Gamma-gliadin & vacuole & storage protein & 0.0233 & 0.042 & 7 & 7 & 19 \\
\hline TraesCS7D01G168000.1 & Alpah-Al & extracellular & stress response & 0.0209 & 0.038 & 6 & 11 & 22 \\
\hline TraesCS7D01G284900.2 & AGPase & plastid & major $\mathrm{CHO}$ metabolism & 0.0205 & 0.037 & 4 & 4 & 5 \\
\hline TraesCS1B01G294300.1 & HSP70 & cytosol & chaperone & 0.017 & 0.031 & 7 & 18 & 32 \\
\hline TraesCS1A01G066100.1 & Globulin-11S & vacuole & storage protein & 0.0167 & 0.03 & 6 & 27 & 49 \\
\hline TraesCS7D01G031700.1 & Gliadin-like avenin & vacuole & storage protein & 0.0145 & 0.026 & 6 & 14 & 32 \\
\hline TraesCS5D01G268000.1 & HSP9O & cytosol & chaperone & 0.0137 & 0.025 & 9 & 234 & 432 \\
\hline TraesCS5D01G020100.1 & Enolase & cytosol & glycolysis & 0.0113 & 0.02 & 9 & 14 & 28 \\
\hline TraesCS2A01G385900.1 & VPE & vacuole & protein degradation & 0.0091 & 0.016 & 3 & 6 & 8 \\
\hline TraesCS3B01G186100.1 & $\mathrm{RBCL}$ & plastid & photosynthesis & 0.0091 & 0.016 & 7 & 10 & 17 \\
\hline TraesCS4D01G267600.2 & CDC48-like & cytosol & cell function & 0.0085 & 0.015 & 6 & 6 & 11 \\
\hline TraesCS1B01G443100.1 & GTP-binding protein & cytosol & signalling & 0.0084 & 0.015 & 6 & 12 & 19 \\
\hline TraesCS4D01G250000.1 & Alpha-Al & golgi & stress response & 0.0083 & 0.015 & 3 & 12 & 16 \\
\hline TraesCS4A01G281500.1 & SND1 & cytosol & RNA regulation & 0.0077 & 0.014 & 9 & 66 & 93 \\
\hline TraesCS7D01G454200.1 & Beta-Tubulin & cytosol & cell function & 0.0076 & 0.014 & 9 & 121 & 260 \\
\hline
\end{tabular}

The wheat genome first Traes ID of the protein group, short protein name, subcellular location (from cropPAL.org) and functional category (from MapMan) are included. The number of biological replicates (Brep No.), number of unique peptides (Pep No.) and number of mass spectra hits (Spectra No.) for each protein are also shown. ATP Cost (\%) column shows the proportion of ATP energy cost to total ATP production $\left(55.77 \mu \mathrm{mol}_{\text {grain }}^{-1} \mathrm{~d}^{-1}\right)$ based on respiratory rate measurements. 
a

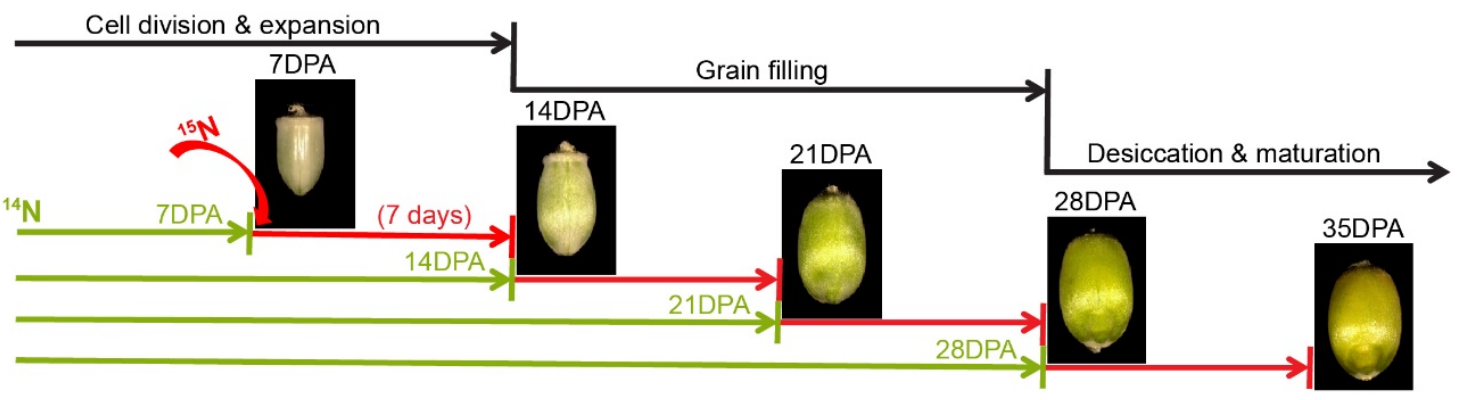

\section{b}

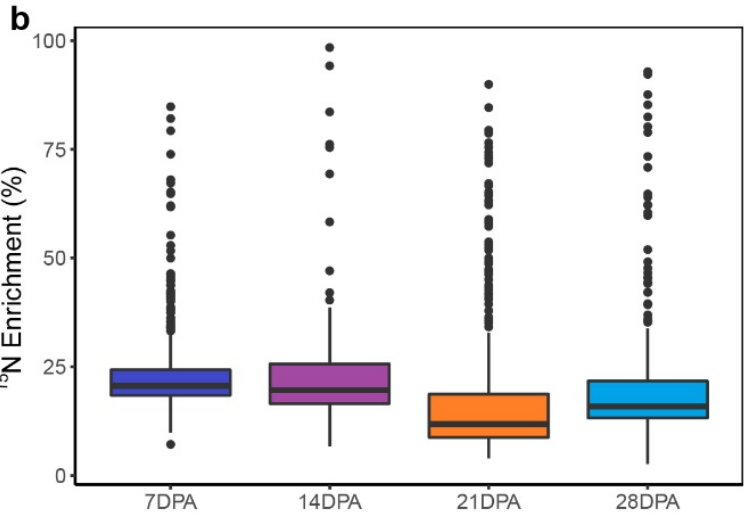

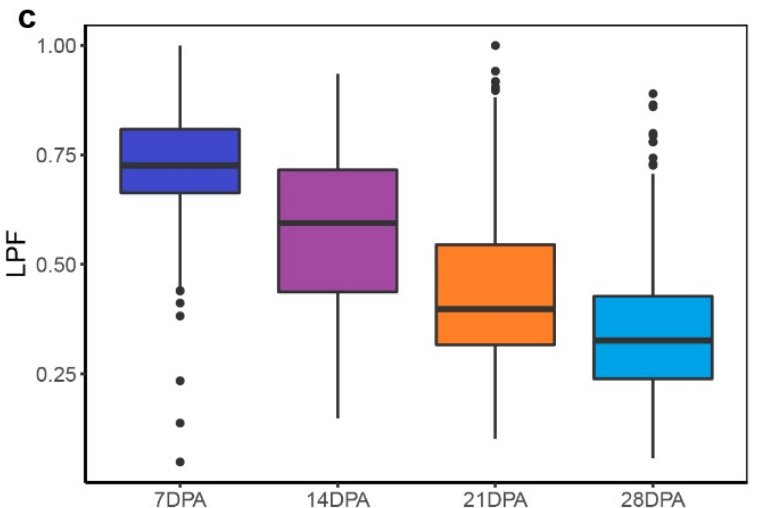

914 Extended Data Fig. 1. I Optimisation of in vivo grain protein labelling approach during grain development. a, The nitrogen stable-isotope ${ }^{15} \mathrm{~N}$ was used in this research and provided to plants as $\mathrm{N}$-salts in hydroponic solutions. A fixed period of 7 days of continuous labelling was performed but was started at 7, 14, 21 or 28 days post anthesis (DPA), respectively. A representative grain image from each time point and a brief grain growth stage description is shown. $\mathbf{b}$, The degree of nitrogen incorporation in the labelled peptides after 7 days of labelling at each growth stage is shown as ${ }^{15} \mathrm{~N}$ enrichment level. c, The labelled protein fraction (LFP) showing the ratio of the abundance of ${ }^{15} \mathrm{~N}$ labelled protein to total peptide abundance (natural abundance protein $+{ }^{15} \mathrm{~N}$-labelled protein) after 7 days of labelling at each growth stage. 


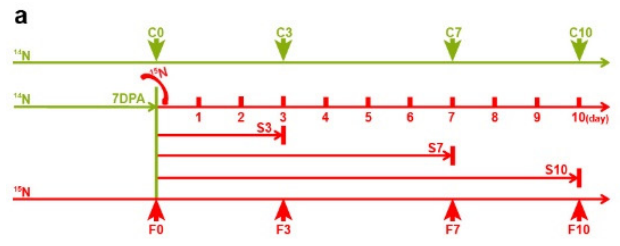

b
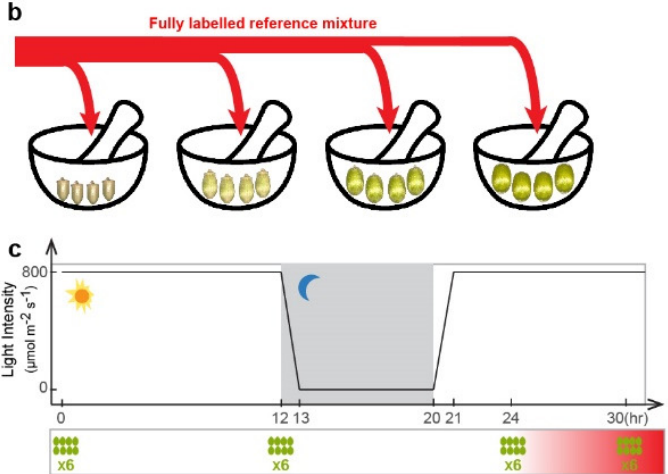

d

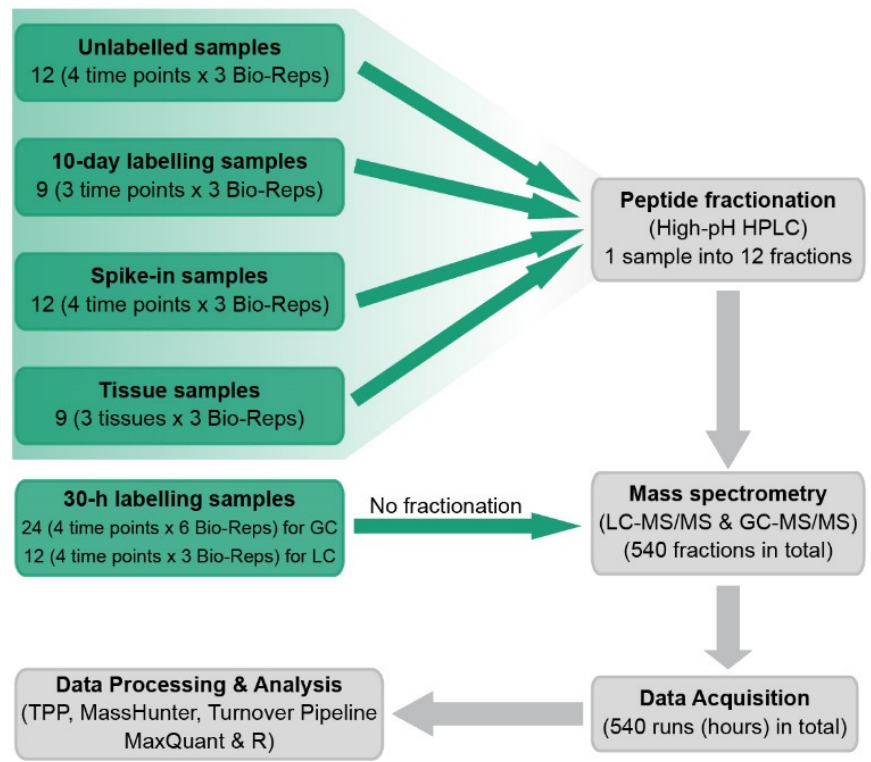

Extended Data Fig. 2. I A flow diagram of experiment design, sample preparation, MS data acquisition and analysis. a, 10-day progressive labelling experiment for grain protein turnover rates measurement. Labelling started at 7DPA, and samples were collected after 3 days (S3), 7 days (S7) and 10 days (S10) of ${ }^{15} \mathrm{~N}$ labelling. The unlabelled samples ( $\mathrm{C} 0$ to $\mathrm{C} 10$ ) and fully labelled samples (F0 to F10, internal reference) at corresponding time points were also collected. Eight grains from the middle of an ear were collected as a biological replicate, and in total three biological replicates were harvested. b, A spike-in approach was developed to measure individual wheat grain protein FCP during grain development. The same amount of a fully labelled reference mixture (100 $\mathrm{mg}$ in this study) was spiked into four grains at each time point, where the reference mixture powder was prepared by pooling together eight fully labelled grains of each time point. c, 30-h progressive labelling experiment for lag time estimation. Using 7DPA plants, samples were collected at 0, 12, 24, 30 hours after labelling, and 8 grains from the middle of an ear were collected as a biological replicate and six biological replicates were collected. $\mathbf{d}$, a flow diagram of sample preparation, mass spectrometry data acquisition and afterward data analysis. The 12 30-h progressive labelling samples were used for metabolite measurements by GC-MS/MS and peptide measurements by LC-MS/MS. 


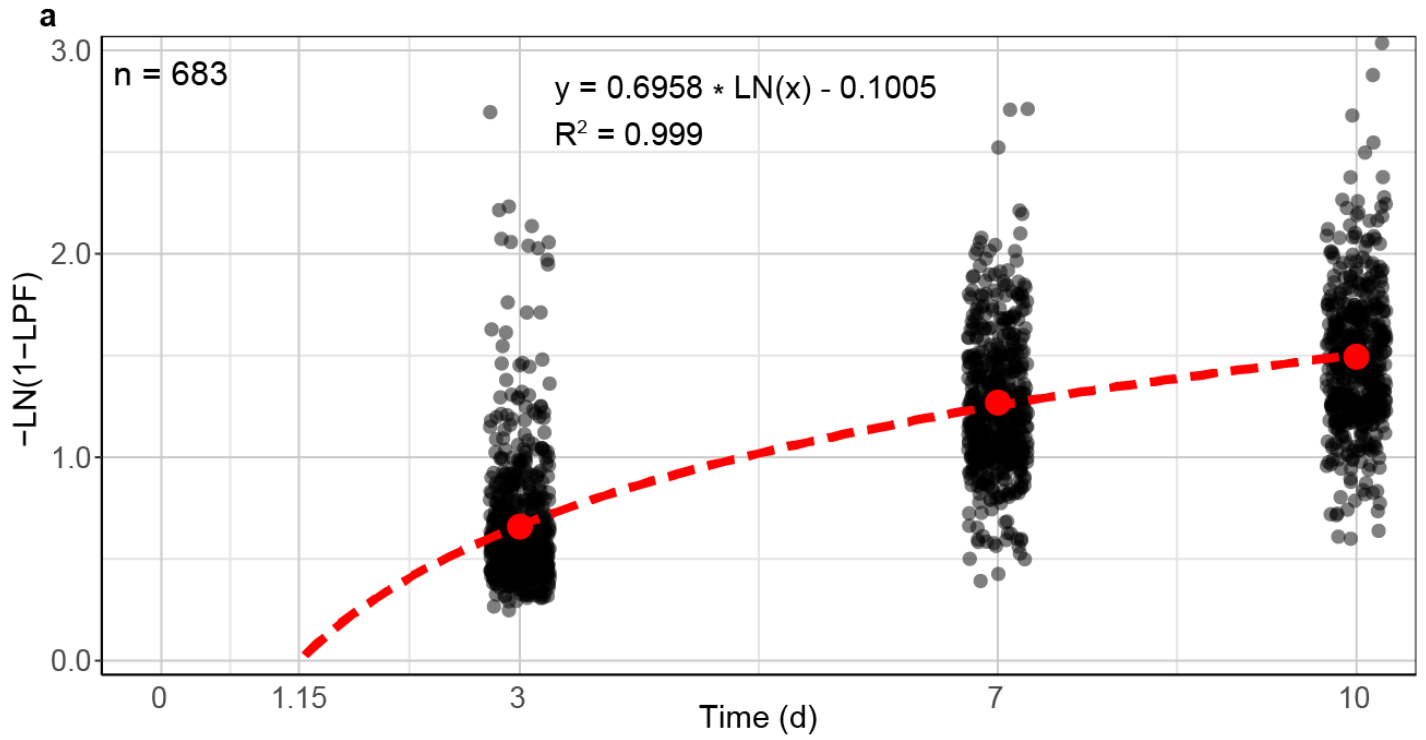

b

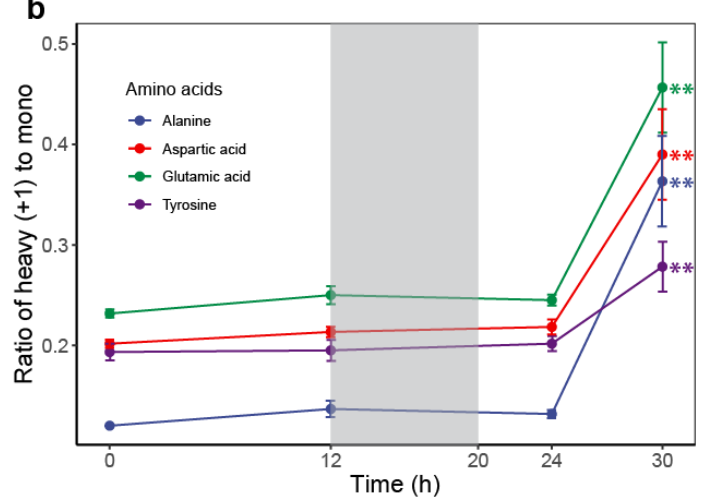

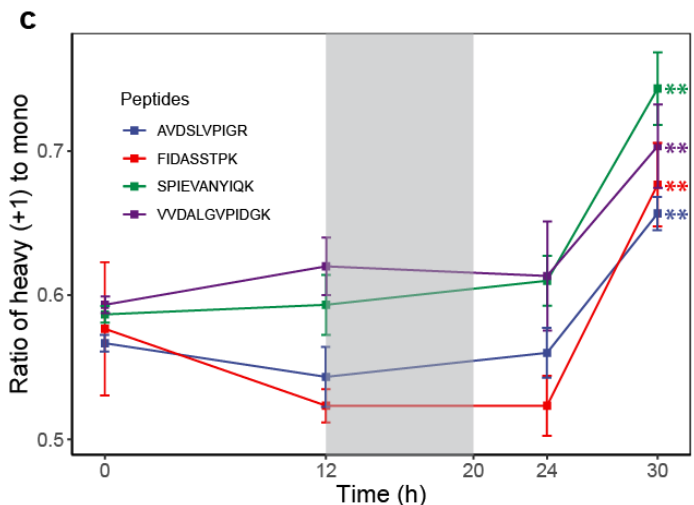

Extended Data Fig. 3. I The time lag of label incorporation into wheat grain proteins. a, The estimation of lag time of incorporation into proteins via logarithmic regression of the inverse of the natural log of natural abundance protein (1-LPF). The dashed red line demonstrated the logarithmic regression model using the mean value (red dots) of each time point. The formula of the logarithmic regression model and its $\mathrm{R}$-square are shown on the top of the scatter plot. $\mathbf{b}$, The ratio of heavy $(+1)$ to mono abundance over the time course of 4 example amino acids measured by GC-MS. Six biological replicates were conducted. $c$, The ratio of heavy $(+1)$ to mono abundance over time course of 4 example peptides measured by LC-MS/MS. Three biological replicates, three of the six used for the GC analysis, were conducted. The shade area represents night time. One-way ANOVA p-value $<0.01$ (asterisks). Actual mass spectrum peaks of the representative amino acid and peptide are shown in Extended Data Fig. 4. Detailed data and statistical test results involved in this analysis are listed in Supplementary Data 2. 
bioRxiv preprint doi: https://doi.org/10.1101/2021.06.15.448508; this version posted June 15,2021 . The copyright holder for this preprint (which was not certified by peer review) is the author/funder, who has granted bioRxiv a license to display the preprint in perpetuity. It is made available under aCC-BY-NC-ND 4.0 International license.

a

Rep1

a $\quad$ o

Oh $12 \mathrm{~h}$ $24 \mathrm{~h}$ $30 \mathrm{~h}$

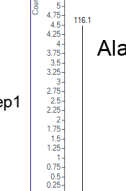

Alanine

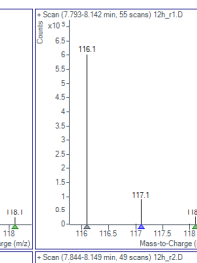

Rep2

Rep6

Rep4 513.8; +1 m/z: 514.3, +2 m/z: 514.8 and +3 m/z: 515.3.

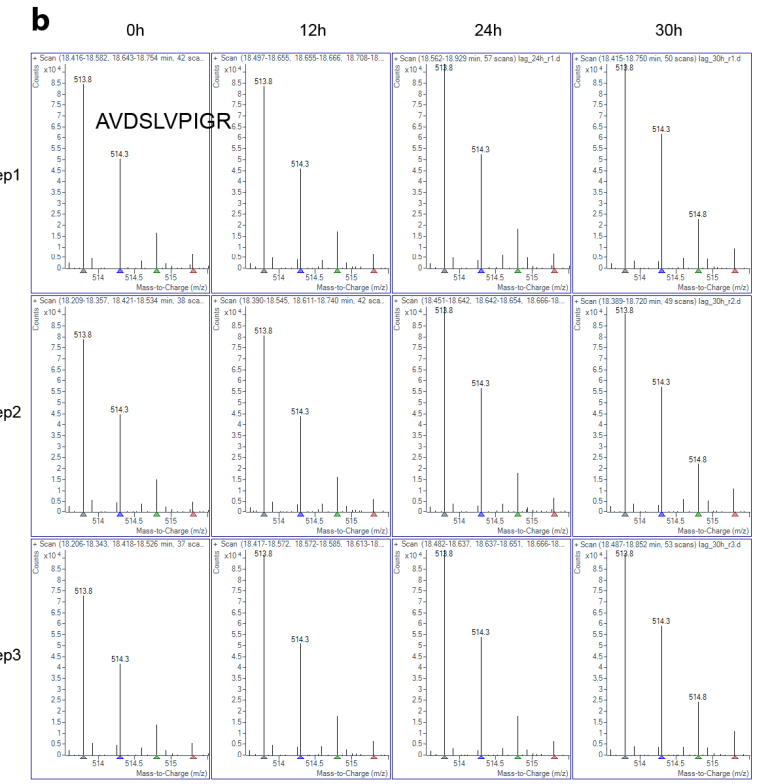

Extended Data Fig. 4. | Mass spectrum of the change from mono to mono + labelled abundances of amino acids and peptides over a 30-h time course to estimate labelling lag time. a, Example mass spectrum peaks of mono and mono + labelled abundance of alanine over the 30h time course. Unlabelled m/z: $161.1 ;+1 \mathrm{~m} / \mathrm{z}$ : 117.1. b, Mass spectrum peaks of mono and mono + labelled abundance of the representative peptide (AVDSLVPIGR) over the $30 \mathrm{~h}$ time course. Unlabelled $\mathrm{m} / \mathrm{z}$ : 


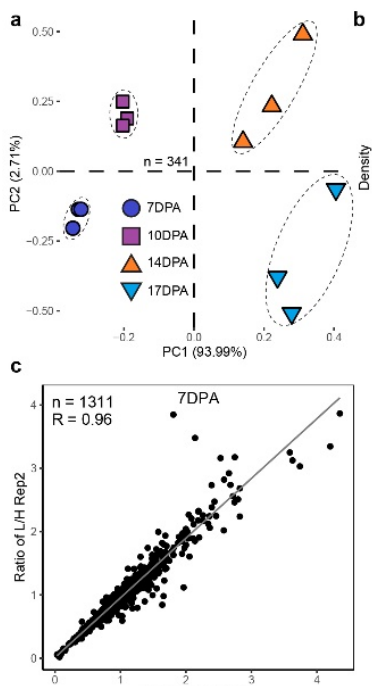

d
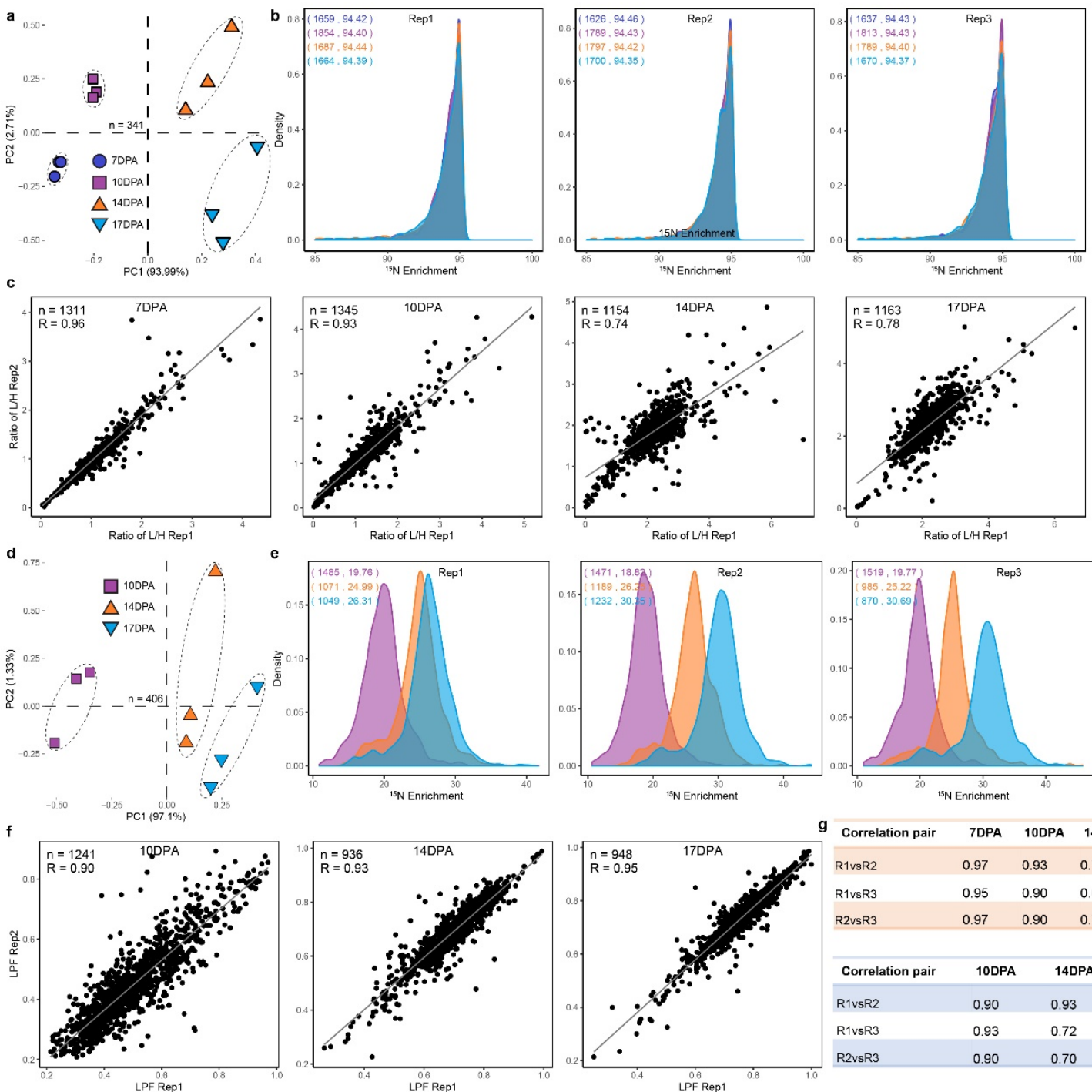

Ratio of L/H Rep1
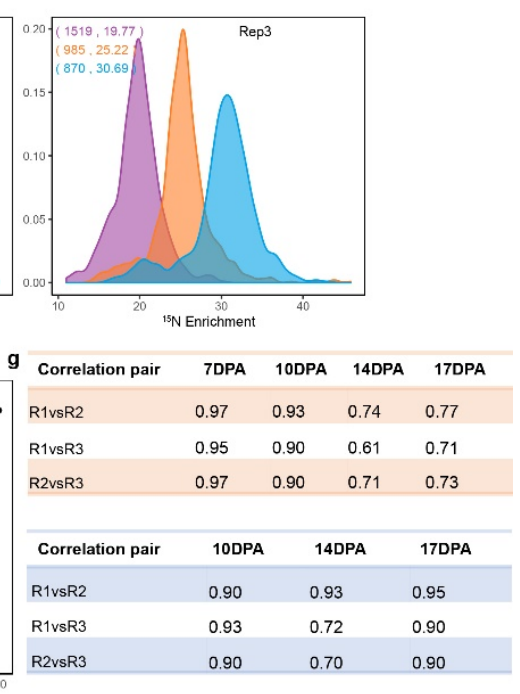

Extended Data Fig. 5. | Data quality verification of spike-in and progressive labelling data. A series of data quality verifications were conducted before further downstream data analysis. The raw data used for this analysis are provided in Supplementary Data 3. The high quality of raw data was supported by three factors, namely the high correlation coefficient ( 0.84 average) between biological replicates; clear separation of different time point samples in PCA; and consistent nitrogen incorporation ( ${ }^{15} \mathrm{~N}$ enrichment) between biological replicates at a timepoint. a, Principal component analysis of spike-in data. The dashed circles outline biological replicates for each time point. $\mathbf{b}$, The ${ }^{15} \mathrm{~N}$ enrichment level of spike-in data of each time point shown in overlapped density plots. The number of proteins and median of ${ }^{15} \mathrm{~N}$ enrichment of each time point are shown within brackets (7DPA: indigo; 10DPA: purple; 14DPA: orange; 17DPA: turquoise). c, Representative scatter plot showing Pearson correlation coefficient between biological replicate 1 and 2 of spike-in data in light to heavy ratio at each time point. The solid grey line indicates the linear regression model. Data size in number of proteins and the correlation coefficient shown on the top-left corner of the plot. Correlation coefficient of all possible pairs are shown in the upper panel in $\mathbf{g}$. $\mathbf{d}$, $\mathbf{e}$ and $\mathbf{f}$ showing data verification result of progressive labelling data using the same analysis strategies as in $A, B$ and $C$ respectively. $G$, The Pearson correlation coefficient of all possible pairs of spike-in (upper panel) and progressive labelling data (lower panel). 


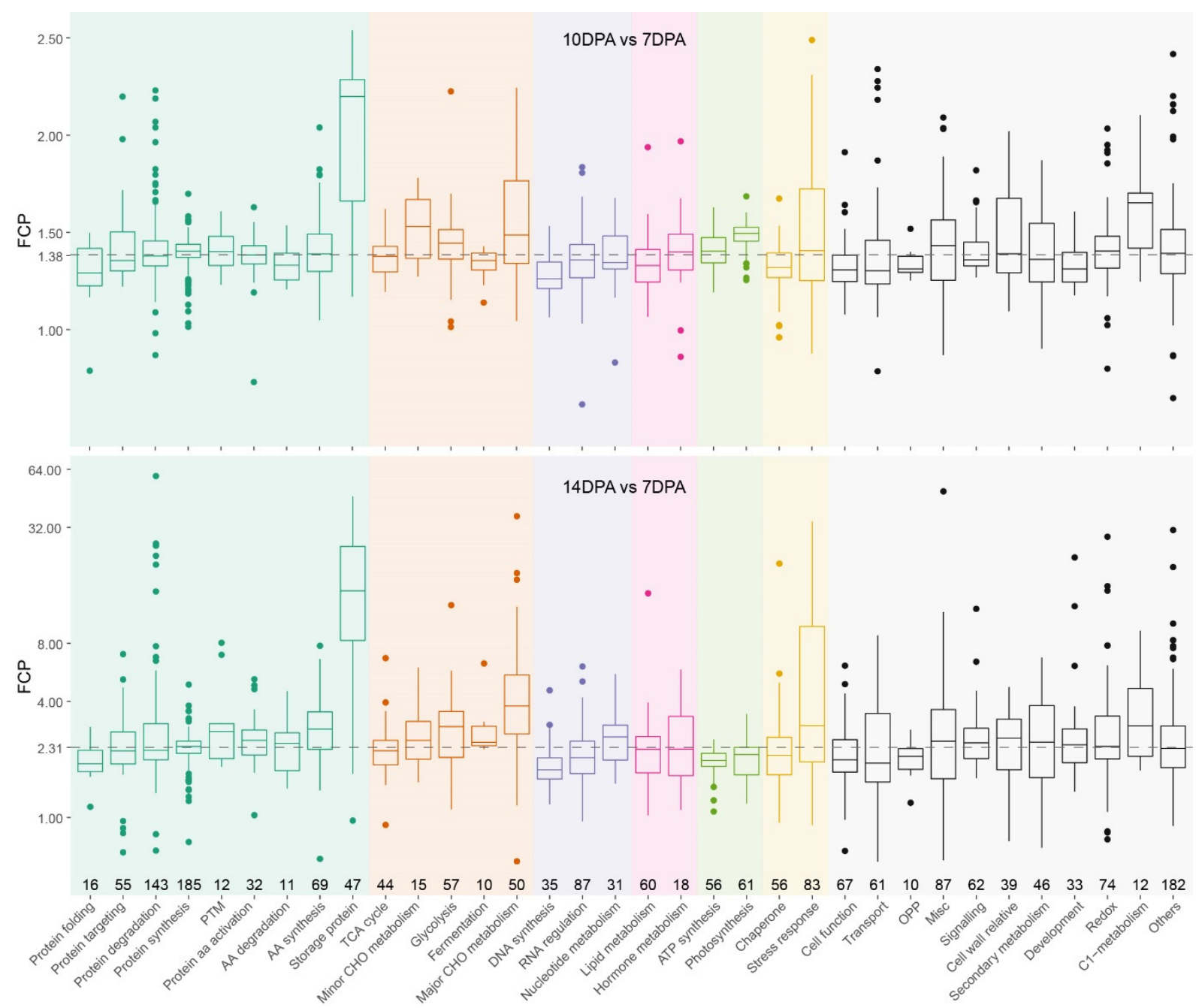

Extended Data Fig. 6. | The individual FCP of wheat grain proteins at DPA 10 and DPA 14 summarized by their functional categories. 34 categories ( $\geq 10$ proteins) were displayed, and the rest of the categories ( $<10$ proteins) were grouped into 'Others'. The number of proteins for each functional category (MapMan bin) is displayed along with $\mathrm{x}$-axis, and boxes within each superior category are sorted by increasing order of median FCP. The $y$-axis is log2 transformed, and the dashed line shows the overall median FCP. Pairwise t-test results between categories are listed on Supplementary Data 4b. Colours represent to broad categories: Amino acid metabolism (Green), Carbohydrate metabolism (Orange-red), Nucleotide metabolism (Purple), Lipid metabolism (Pink), Energy producing (Lawngreen), Stress response (Gold) and 'Other' categories (Black). 

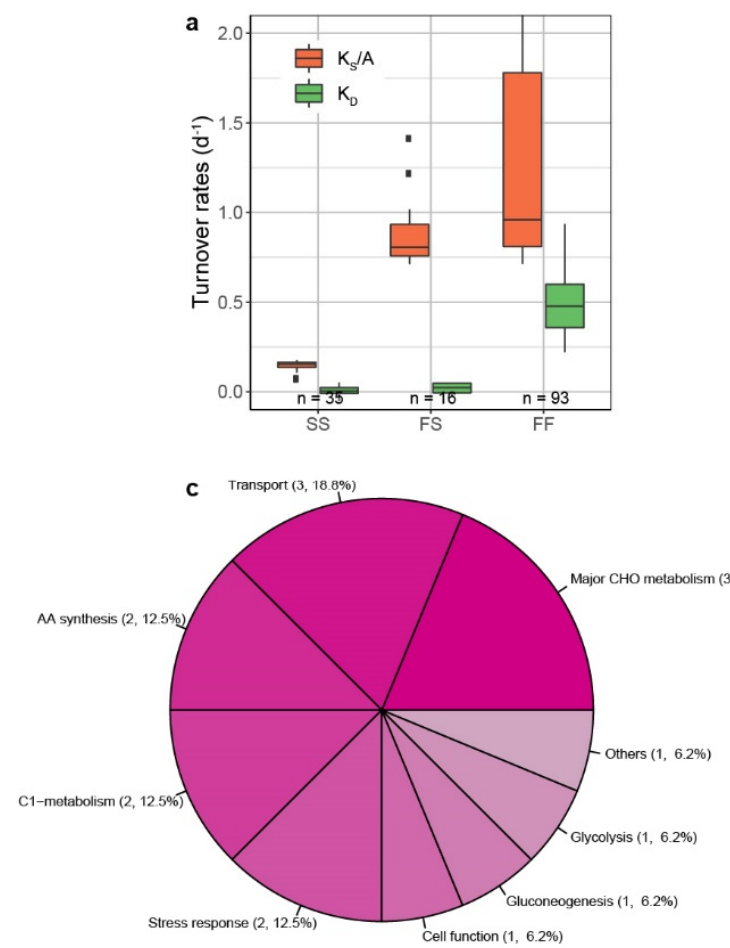

b
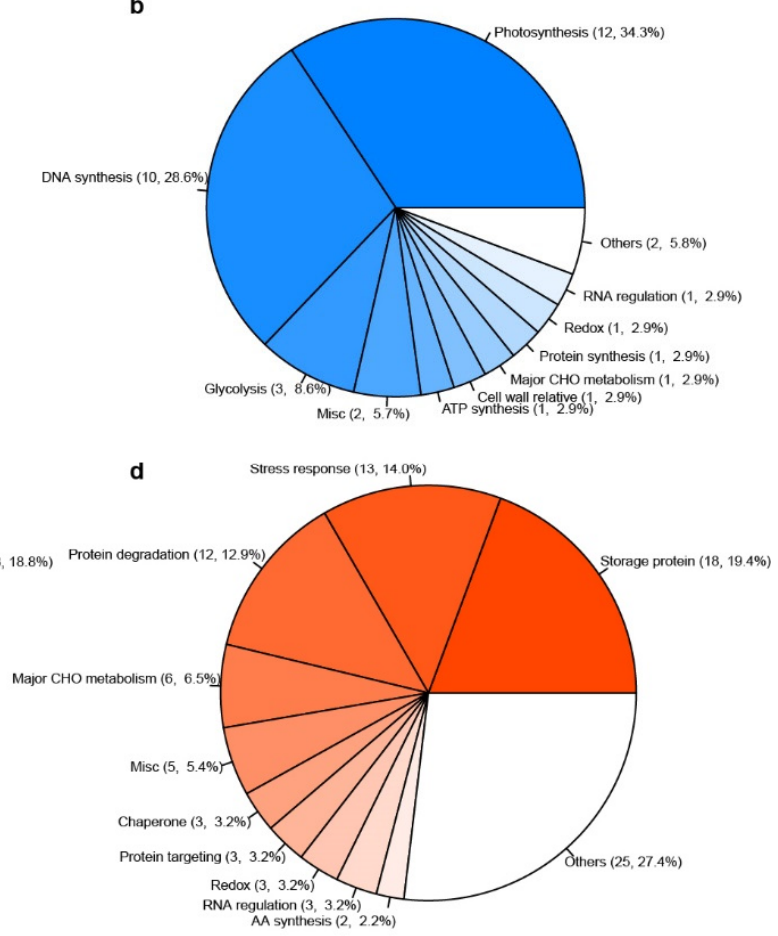

Extended Data Fig. 7. | Relatively slow and fast turning over wheat grain proteins during grain development. A total of 678 proteins, defined as relatively fast or slow turning over proteins, were identified within the dataset (Supplementary Data $5 b$ ). These proteins were further grouped into three categories according to their turnover characteristics, house-keeping proteins (SS: having both relatively slow $K_{S} / A$ and $K_{D}$ rates), induced but stable proteins (FS: having relatively fast $K_{S} / A$ but relatively slow $K_{D}$ ) and rapidly-cycling proteins (FF: having both relative fast $K_{S} / A$ and $K_{D}$ rates). $a, B o x$ plots of the averaged $K_{S} / A$ and $K_{D}$ rates calculated over three time points for the SS, FS and FF categories. The number of proteins in each category are shown along with $\mathrm{x}$-axis. Statistical results derived from one-way ANOVA and Tukey's HSD were shown in Supplementary Data 5c. b. Pie plot of functional categories of house-keeping proteins (SS). c, Pie plot of functional categories of induced but stable proteins (FS). d, Pie plot of functional categories of rapidly-cycling (FF). Only top 10 categories are shown if total functional categories $\geq 10$, and the rest of categories are assigned into Others. 


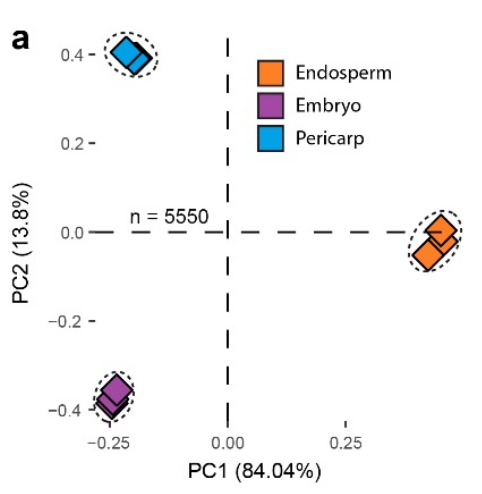

C

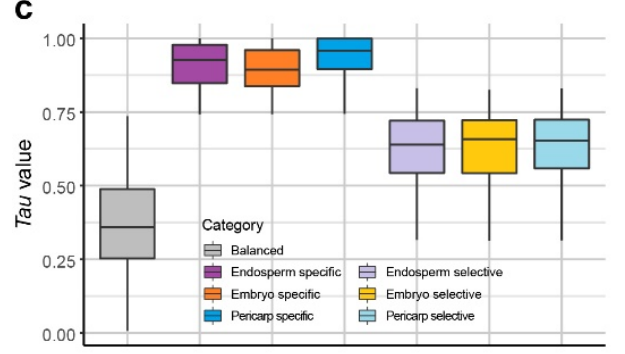

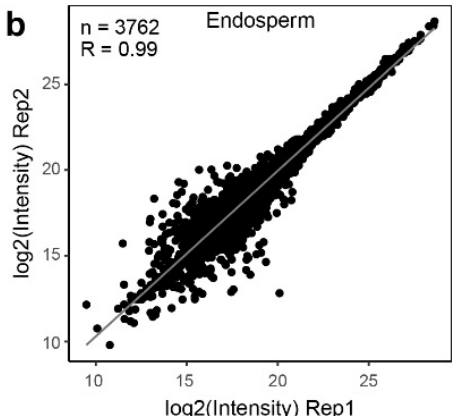

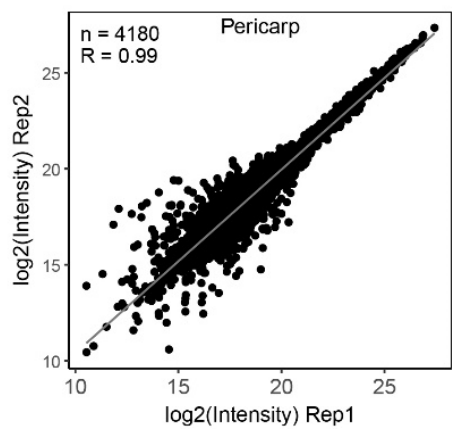

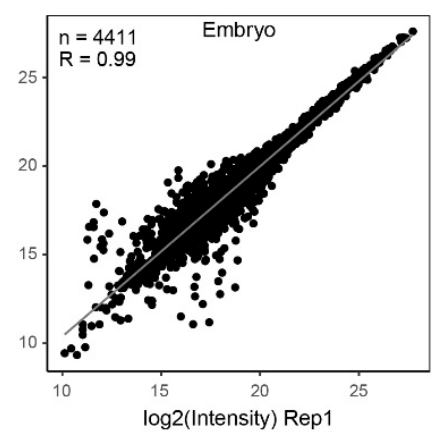

Endosperm $\quad 0.99 \quad 0.99 \quad 0.99$

$\begin{array}{llll}\text { Embryo } & 0.99 & 0.99 & 0.99\end{array}$

$\begin{array}{llll}\text { Pericarp } & 0.99 & 0.99 & 0.99\end{array}$
Tissues/Pair R1vsR2 R1vsR3 R2vsR3

Extended Data Fig. 8. I Data quality verification of wheat grain tissue data sets. a, Principal component analysis of 5550 protein abundances used for this analysis (Supplementary Data 6). Dashed circles encompass three biological replicates for each time point. $\mathbf{b}$, Representative scatter plots showing Pearson correlation coefficient between biological replicate 1 and 2 of log2 transformed protein abundance intensity for each tissue. The solid grey line shows the linear regression model. The number of proteins identified and the correlation coefficient between replicates is shown on the topleft corner of the plot. The table shows correlation coefficients of all possible pairs. c, The box plot of Tau value for the seven protein expression categories.

1052

1053

1054

1055

1056

1057

1058

1059

1060

1061 

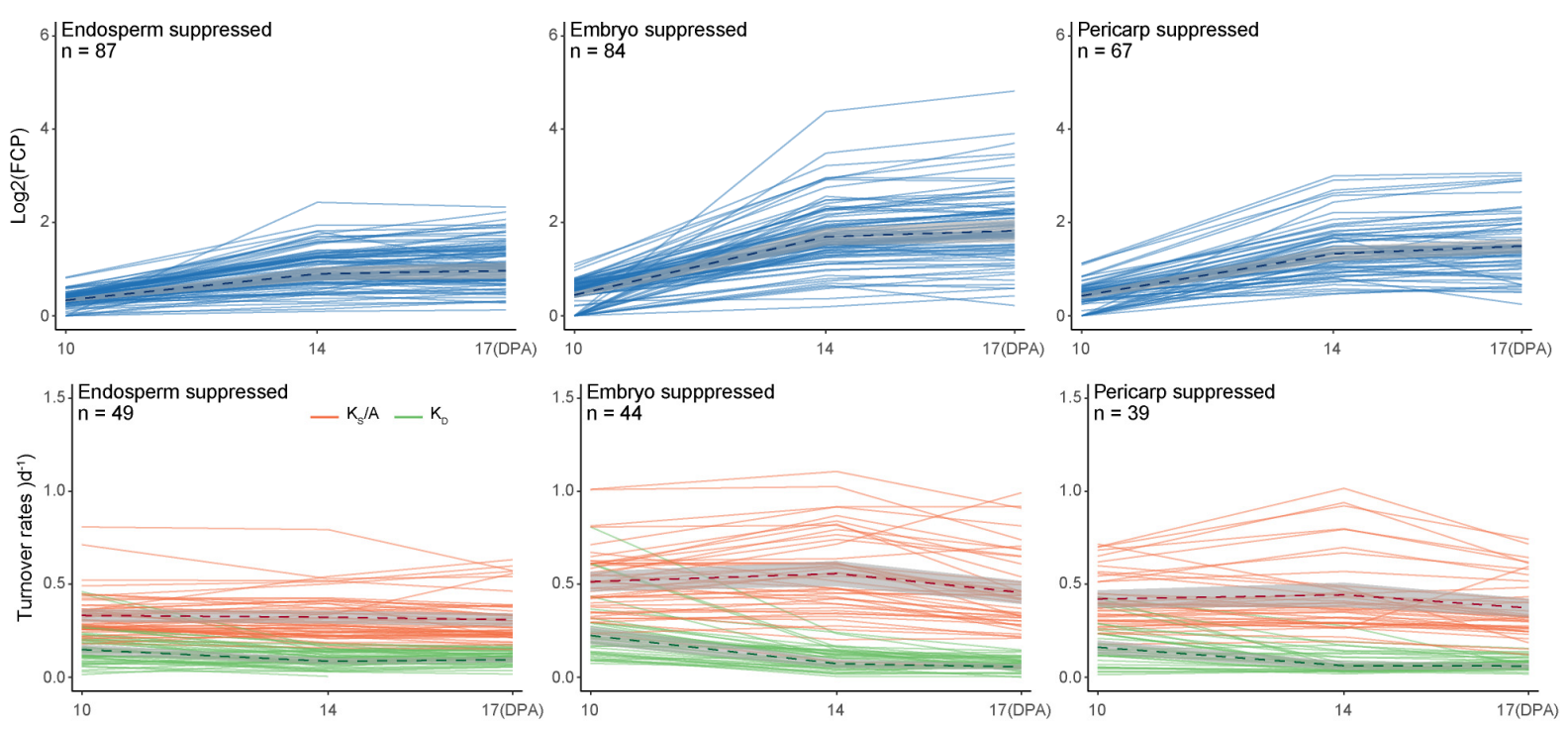

Extended Data Fig. 9. | Changes in FCP and turnover rate profiles of proteins present in a lower abundance in a given tissue type during grain development. Only proteins having values (FCP or turnover rates) at all three time points are included in the analysis. The dashed lines demonstrate the mean values, and the grey shade areas show the $95 \%$ confidence intervals.

1070 

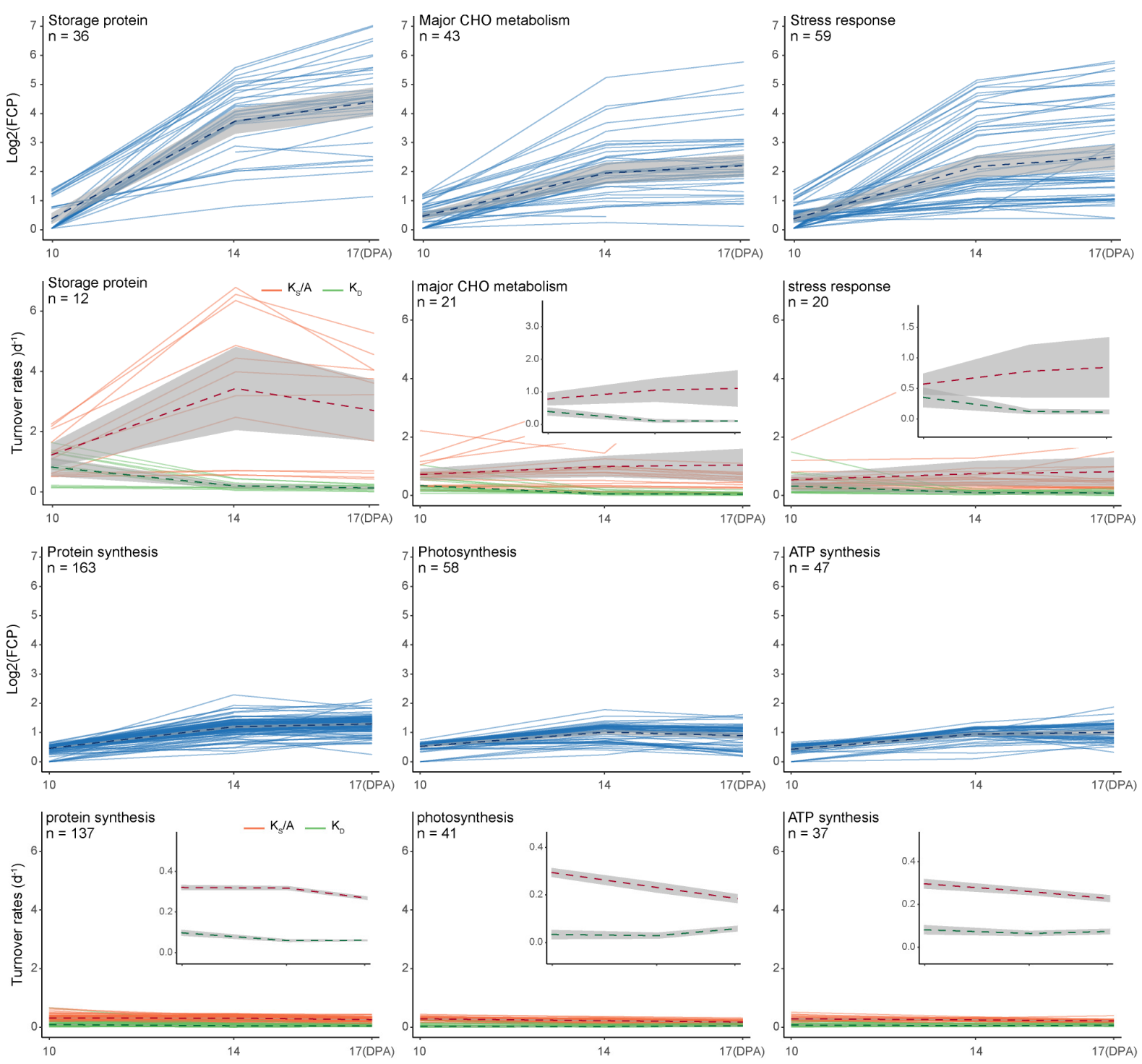

Extended Data Fig. 10. | Changes in turnover rates of proteins with high (top 6 graphs) and low (bottom 6 graphs) FCP during grain development. Each pattern includes three example functional categories. FCP (Blue), protein synthesis $\mathrm{K}_{\mathrm{A}} / \mathrm{S}$ (Orange) and protein degradation $\mathrm{K}_{\mathrm{D}}$ (Green) values are shown. In each functional category, only proteins with FCP or turnover rates measured at all three time points are included. The number of proteins included in each functional category is shown. Dashed lines indicate the mean values, and the grey shade areas show the $95 \%$ confidence intervals. The optimized $y$-axis scale version of turnover rates data are inserted to highlight the change pattern. 


\section{Supplementary information}

1098

1099

Supplementary Data 1

1100

Full data list of grain fresh weight, grain respiration rate and total grain ATP production.

1101

\section{Supplementary Data 2}

Full data list of lag time modelling, GC-MS/MS data and LC-MS/MS data.

\section{Supplementary Data 3}

1104 Full data list used for data quality control analysis.

\section{Supplementary Data 4}

1106

Full data list of wheat grain individual FCP values during grain development.

\section{Supplementary Data 5}

1108 Full data list of wheat grain protein turnover rates during grain development.

1109 Supplementary Data 6

1110 Full data list of protein relative abundance for embryo, endosperm and pericarp proteomes.

\section{Supplementary Data 7}

1112 Full data list of ATP energy budget used for wheat grain protein turnover during grain development.

1113 Supplementary Data 8

1114 Full data list of wheat grain key storage proteins accumulation profiles during grain development. 